\title{
TECHNOLOGY ON TRIAL: FACILITATIVE AND PREJUDICIAL EFFECTS OF COMPUTER-GENERATED ANIMATIONS ON JURORS' LEGAL JUDGMENTS
}

\author{
by \\ Emma Rempel
}

Bachelor of Arts (Hons) in Psychology, University of Guelph, 2015

A thesis presented to Ryerson University

in partial fulfillment of the requirements for the degree of

Master of Arts in the program of Psychology

Ryerson University

Toronto, Ontario, Canada, 2019

(C) Emma Rempel, 2019 


\section{AUTHOR'S DECLARATION FOR ELECTRONIC SUBMISSION OF A THESIS}

I hereby declare that I am the sole author of this thesis. This is a true copy of the thesis, including any required final revision, as accepted by my examiners.

I authorize Ryerson University to lend this thesis to other institutions or individuals for the purpose of scholarly research.

I further authorize Ryerson University to reproduce this thesis by photocopying or by other means. In total or in part, at the request of other institutions or individuals for the purpose of scholarly research.

I understand that my thesis may be made electronically available to the public. 
Technology on Trial: Facilitative and Prejudicial Effects of Computer-Generated Animations on Jurors’ Legal Judgments

Master of Arts, 2019

Emma Rempel

Psychology

Ryerson University

The recent emergence of electronic courtrooms (i.e., courtrooms that are equipped with advanced digital technologies) has generated novel ways to present evidence to jurors. Computer-generated animations, which recreate or illustrate the alleged sequence of events in a crime, are increasingly being used by lawyers to present testimonial evidence to jurors. The current study used a 3 (modality: oral vs. static visual vs. animation) x 2 (congruence: incongruent vs. congruent) between-subjects design to investigate whether presentation modality and evidence congruence affect jurors' ability to properly evaluate evidence and render 'accurate' verdicts. In a laboratory setting, mock jurors $(\mathrm{N}=238)$ read a transcript from a fictitious second-degree murder trial. Participants read testimony from eight witnesses, and heard the oral testimony of the defendant with a static visual aid, a computer-generated animation, or no visual aid. Results demonstrated that mock jurors were more likely to acquit the defendant when his testimony was illustrated with a computer-generated animation compared to a static visual aid or with no additional aid. Research in this area can inform the development of evidentiary regulations which adequately govern the admissibility of computer-generated animations in the courtroom, so as ensure that they are used in a way that maintains a defendant's right to a fair trial. Keywords: computer-generated evidence, computer animations, legal decision-making, information processing, electronic courtrooms 


\section{Acknowledgements}

I would like to express my sincere gratitude to my supervisor, Dr. Tara Burke, who has consistently supported my development as a scholar, and who has assisted immensely at all stages of this project. Without Dr. Burke, the idea for my thesis would never have materialized into the final product that I proudly look upon today, and I am infinitely grateful for her consistent encouragement, patience, and her expertise in psychology and law.

I would also like to acknowledge Dr. Stephen Want, who has played a fundamental role in brainstorming, developing and refining this project, both as a professor and as a supervisory committee member; without his keen insights and knowledge this project would not have been possible. I am so appreciative to have had Dr. John Turtle as a member on my supervisory committee; his comments and recommendations during my defence were immensely valuable.

To my professors at Ryerson, thank you for supporting my journey as a master's student. I have learned so much since I began my graduate career, and I owe so much of my success to the educational excellence that I have received at this institution. It is an honour to surround myself with such intelligent and generous faculty members.

To my lab mates, Leah and Lesley, there really hasn't been a dull moment in the PAL lab since the three of us joined forces. I look up to you both as mentors, and as close friends, and the opportunity to watch us grow academically and work together toward our goals has been a blessing. I'm excited to see what the future has in store for us!

Finally, I thank my family, friends and partner, Ryan, for their love and support throughout this process, and for keeping me (relatively) sane. I could not have done this without any of you. 


\section{Table of Contents}

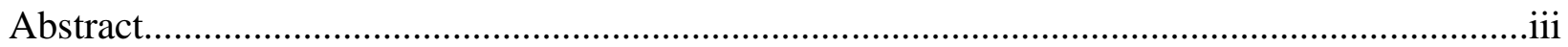

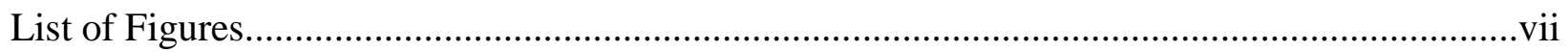

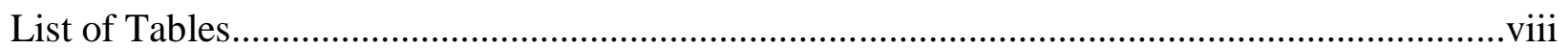

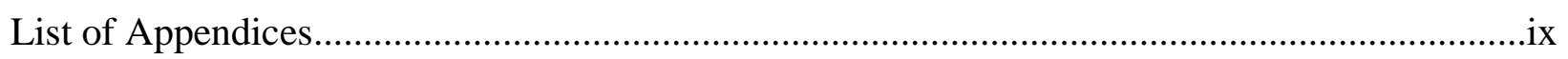

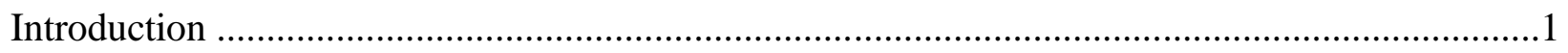

The North American Trial System...............................................................................

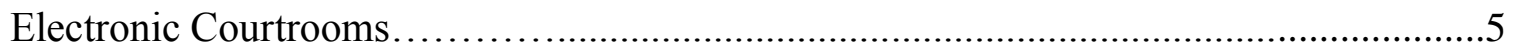

Computer-Generated Evidence.............................................................................

Admissibility Regulations for Computer-Generated Evidence............................................10

Cognitive Processing of Visual Evidence ……………......................................................14

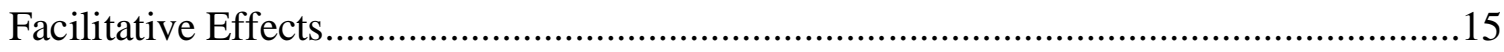

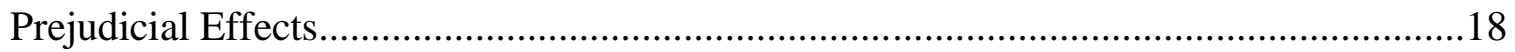

Controlled Experimental Studies on Computer-Generated Animations.............................24

Summary

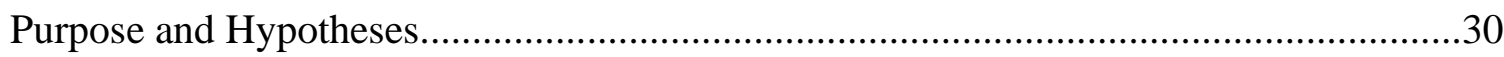

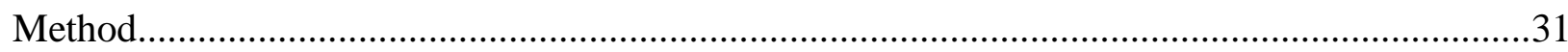

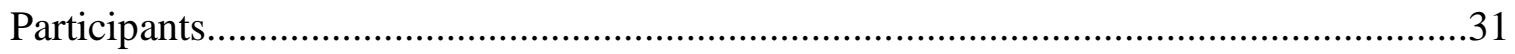

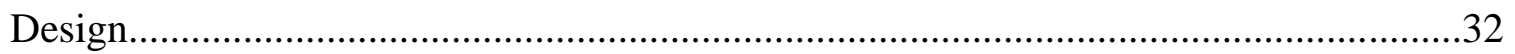

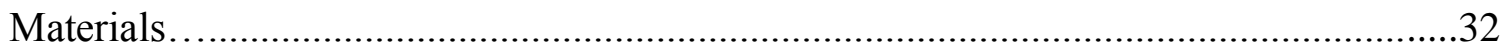

Procedure 
Results

Verdicts. 40

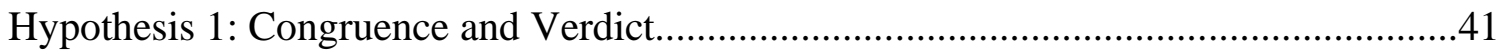

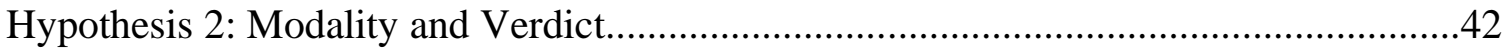

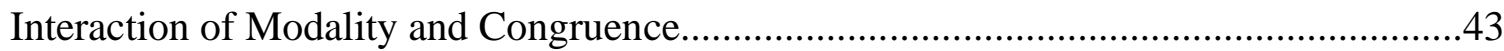

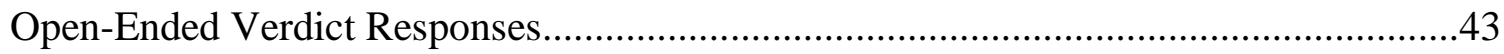

Covariate Predictors of Verdict..............................................................................44

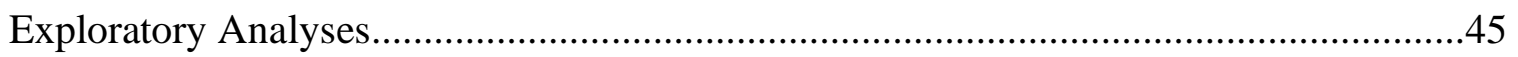

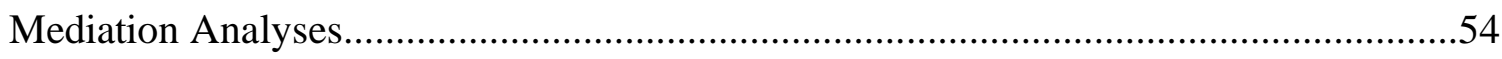

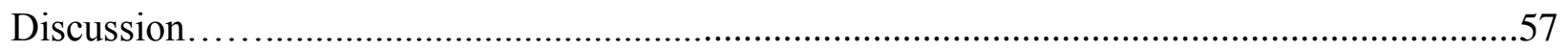

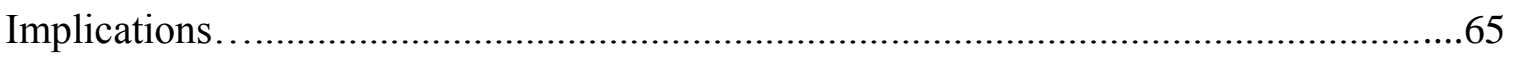

Limitations and Future Directions.....................................................................6

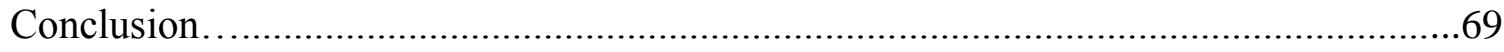

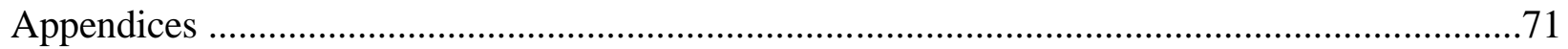

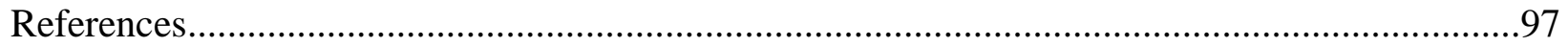




\section{List of Figures}

Figure 1. Percentage of not-guilty verdicts by congruence condition 41

Figure 2. Percentage of not-guilty verdicts by modality condition 42

Figure 3. Confidence in verdict by evidence modality condition 47

Figure 4. Probability of guilt estimates by modality condition $\quad 48$

Figure 5. Perceptions of the Prosecution's case strength as a mediator 56

Figure 6. Perceptions of the Defendant's credibility as a mediator 57 


\section{List of Tables}

Table 1. Distribution of Verdict Frequencies as a Function of Evidence Congruence and Modality

Table 2. Confidence in Verdict as a Function of Evidence Congruence and Modality

Table 3. Probability of Guilt Estimates as a Function of Evidence Congruence and Modality

Table 4. Case Strength as a Function of Evidence Congruence and Modality

Table 5. Attorney Efficacy as Function of Evidence Congruence and Modality

Table 6. Defendant's Credibility as a Function of Evidence Congruence and Modality 


\section{List of Appendices}

Appendix A. List of Witnesses $\quad 71$

Appendix B. Defendant's Testimony Transcript $\quad 72$

$\begin{array}{ll}\text { Appendix C. Static Visual Images } & \mathbf{7 4}\end{array}$

$\begin{array}{ll}\text { Appendix D. Evidence Strength Individual Items } & 77\end{array}$

$\begin{array}{ll}\text { Appendix E. Perceptions of Police Scale } & 80\end{array}$

Appendix F. Attitudes Toward Science and Technology Scale $\quad 82$

$\begin{array}{ll}\text { Appendix G. Juror Bias Scale } & \mathbf{8 3}\end{array}$

Appendix H. Demographics Questionnaire $\quad 85$

Appendix I. Consent Form $\quad 86$

Appendix J. Juror Instructions $\quad 89$

$\begin{array}{ll}\text { Appendix K. Verdict Instructions } & 93\end{array}$

Appendix L. Verdict Decision Form 94

$\begin{array}{ll}\text { Appendix M. Debriefing Form } & 95\end{array}$

$\begin{array}{ll}\text { Appendix N. SONA Advertisement } & 96\end{array}$ 
The Canadian criminal justice system consists of multiple court levels with responsibility shared between federal and provincial governments (Department of Justice Canada, 2017). These court systems are responsible for administering justice by having decision makers determine the culpability of accused persons, as well as sentencing for those who are found guilty (Maxwell, 2017). According to correctional services data, 325,000 cases are adjudicated in the Canadian adult criminal system each year, approximately $63 \%$ of which result in a conviction (Maxwell, 2017). For the accused, the prospect of a criminal trial is daunting; individuals face a number of punitive outcomes upon conviction, not least of which being a loss of their personal liberty and freedoms (Department of Justice Canada, 2017).

Although the Charter of Rights and Freedoms and common law exist to protect the rights of the accused, miscarriages of justice do occur. At present, Canada lacks a database to track the national incidence of wrongful conviction; in the United States, the National Registry of Exonerations (2019) includes approximately 2,438 wrongfully convicted individuals. Some criminal justice scholars have suggested that the true incidence of wrongful convictions in the United States is substantially higher, estimating that between 1-3\% of the total number of convictions in the United States are wrongful (Ramsey \& Frank, 2007; Zalman, Smith \& Kiger, 2008). With a more conservative estimate of the prevalence rate, if only $0.5 \%$ of the convictions in the United States were erroneous, approximately 7,500 innocent persons would be wrongfully convicted in any given year (Huff, 2002).

The process of overturning a conviction has been described by some as akin to Sisyphus ceaselessly trying to roll a heavy boulder up a mountain (Clow, 2017); in other words, convictions are nearly impossible to overturn. In both Canada and the United States, an individual must exhaust all appeals before their case is even considered as a possible miscarriage 
of justice, and a review of an individual's case will only take place in the presence of newly discovered evidence (Criminal Case Review Commission, 2015; Krieger, 2011; Roach, 2012). Of the fraction of cases that are successfully granted an appeal, only about $7-12 \%$ of these appeals will result in a reversal of the original verdict in state court (Waters, Gallegos, Green \& Rozsi, 2015). Given the serious and enduring nature of any single wrongful conviction, it is concerning that the exact number of individuals who have been affected by this miscarriage of justice - both in Canada and the U.S - remains unknown.

A number of high-profile wrongful convictions cases have increased the saliency and awareness of this issue in recent years, which has led to an increase of scholarly research in the area (Findley, 2007). In 2005, the Innocence Network was created, consisting of 67 global organizations whose aim is to prove the innocence of wrongfully convicted individuals and to reform the justice system to prevent future instances of wrongful conviction (Innocence Network, 2019). Innocence Canada represents the Canadian division of the Innocence Network, and is one of three Canadian initiatives aimed at identifying, advocating for and exonerating individuals who have been convicted of a crime they did not commit (Innocence Canada, 2018). In addition to their efforts in supporting and rehabilitating exonerees, the Innocence Project has identified various factors that contribute to wrongful convictions, including false confessions, eyewitness misidentification, incentivized informants, misapplication of forensic science, inadequate defense and government misconduct (Innocence Project, 2017).

According to Rosen (1992) each instance of wrongful conviction demonstrates a unique combination of failures in the criminal justice system that have prevented it from functioning effectively. Contributors to wrongful conviction can, and often do, occur in conjunction with one another, and errors at various stages can contribute to an individual being either wrongfully 
accused or convicted of a crime they did not commit (Huff, 2004). For example, a mistaken eyewitness identification could result in an individual being indicted for an offense they did not commit, and subsequently, inadequate defense at trial could allow this charge to develop into a wrongful conviction. In this regard, the trial process represents a pivotal opportunity for individuals to establish their innocence before the shift from a wrongful accusation to a wrongful conviction occurs.

A recent review by the Innocent Project (2010) found that approximately $18 \%$ of wrongful conviction cases involved a 'harmful error' (i.e., an error compromising the validity of a conviction) by the Prosecution. Prosecutorial misconduct encompasses a number of violations pertaining to transgressions in the courtroom, including misconduct which occurs during evidentiary proceedings, such as: introducing or attempting to introduce inadmissible, inappropriate or inflammatory evidence, using false or misleading evidence in trial proceedings and mischaracterizing the evidence or the facts of the case to the jury (Lawless, 2016). The misuse or mischaracterization of evidence by either legal party can introduce bias into the courtroom, ultimately impeding the course of justice for the accused. In extreme circumstances, the misuse of evidence can result in an innocent person being punished for a crime they did not commit, meanwhile allowing real perpetrators to go free.

Failure by the court system to identify and resolve instances of misconduct can have grave implications, including undermining the integrity of the criminal justice system, and deteriorating public confidence in an institution that is built upon tenets such as effectiveness and fairness (Rosen, 1992). To date, a majority of research on wrongful convictions has focused on errors which occur during the investigative process (e.g., eyewitness misidentification and false confessions), and there have been comparatively few attempts to understand how faulty trial 
processes and procedures can impede the administration of justice. It is therefore crucial to critically examine the trial system in Canada to ensure that individuals are being prosecuted fairly and in accordance with Canada's legal and constitutional structure.

\section{The North American Trial System}

In Canada and the U.S., when defendants are accused of a serious criminal offence (i.e., in Canada, defined as an offense punishable by 5 years or more of imprisonment, or 6 months in the U.S.) they are granted the right to a trial by jury (Canadian Charter of Rights and Freedoms, 1982; U.S. Const. amend. VI). Within the adversarial legal system, a jury trial is typically characterized by a group of twelve, impartial citizens who act as the triers of fact, and a judge who maintains a passive role during trial, with his/her responsibilities limited to ensuring Federal Rules of Evidence and Procedure are being followed (Bala \& Anand, 2013). In contrast to the European inquisitorial system where the judge actively investigates and leads a case (Bala \& Anand, 2013), in the North American system, the members of the jury alone act as fact finders, and are therefore tasked with weighing the case evidence and rendering a verdict (Department of Justice Canada, 2017). During jury deliberations, juror must carefully weigh the presented evidence and come to a reasoned verdict, and thus it is important that they thoroughly evaluate and understand this evidence.

Concerns have been raised that the structure of the adversarial system, which minimizes the role of the presiding judge, may exacerbate instances of injustice in the courtroom by impeding jurors' ability to adequately process evidence (Huff, 2004). With the judge's attention directed to procedural matters, jurors are required to process a vast amount of technical legal information on their own (van Caenegem, 1999). Jurors receive relatively little training or instruction on how to properly weigh evidence, and research has shown that jurors may struggle 
to understand complex case evidence (e.g., Cooper, Bennett \& Sukel, 1996; Hafer, Reynolds \& Obertynski, 1996). In lieu of a judge's assistance, trial attorneys are responsible for guiding jurors through the case evidence, making their own level of competence a focal point of the case. Although jurors are instructed to weigh only the tangible evidence in the case, there is a tendency for them to factor dispositional cues about the lawyer's presentation into their verdicts. Research by Park and Feigenson (2013) showed that when lawyers were perceived by mock jurors as being more prepared, competent and credible, jurors were more likely to render liability judgments in favour of the lawyer's client. Given that the Prosecution is often advantaged by greater monetary and human resources than the Defense, they may be able to present a more compelling and persuasive argument based on the resources available to them - regardless of the actual evidentiary value of their case (Huff, 2004).

In summary, jurors in Canada are encumbered with the substantial responsibility of determining a defendant's culpability with little to no support from the judge (van Caenegem, 1999). Jurors thereby assign a great deal of importance to the testimony and evidence presented by the Prosecution and Defense when deciding their verdicts (Huff, 2004). Given the considerable level of responsibility bestowed on jurors during trial, it is critical that any evidence which is being used by lawyers to implicate a defendant has been validated by the appropriate evidentiary regulations before being admitted into trial.

\section{Electronic Courtrooms}

Courtrooms across North America have recently undergone a number of technological advancements that are changing the way that evidence is presented to and received by jurors. In 1998, the United States Judicial Conference declared courtroom technologies as "necessary and integral," thereby launching a pilot project aimed at incorporating various technologies into 
American courtrooms and arranging for new courtrooms to be built with these technologies in place (DeSario, 2002). In 2001, Canada followed suit on this initiative, announcing a plan that focused on the gradual integration of technology into the justice system over a multi-year period (Ontario Ministry of the Attorney General, 2017). These technological innovations, which include real-time court reporting technologies, video/audio conferencing capabilities, HD monitors in the jury box, internet connections, document cameras and infrared listening devices (Wiggins, 2004), allow for innovative and novel ways to present evidence to jurors. Currently, the vast majority of American jurisdictions have implemented at least one of these high-tech initiatives, forecasting a major overhaul to the landscape of the criminal justice system (Wiggins, 2004).

With the use of digital technology in North American courtrooms steadily rising over the past decade, a majority of judges have embraced these technologies based on their purported facilitative effects on jurors (Dixon, 2012). The digital presentation of courtroom documents is thought to reduce the time required to physically locate documents during trial and to make it easier for attorneys to attract and maintain jurors' attention to relevant portions of the evidence. The use of technology in the courtroom is also expected to enhance the ability of attorneys to explain complex evidence, such as highly technical simulations or scientific concepts, in turn making it easier for jurors to understand this evidence (Aronson \& McMurtrie, 2007; Wiggins, 2004). Previously, these expensive technologies were only available to deep-pocketed law firms, giving them an unfair advantage at trial against less affluent counterparts. Electronic courtrooms allow for the use of technology by either legal party, regardless of financial standing; the increased accessibility of these technologies may 'level the playing field' for legal counsel and promote fairness and equitability at trial (DeSario, 2002). 
Beyond practical and fiscal considerations, jurors appear to be reacting favourably to courtroom technologies. In a 2011 survey by the D.C. superior court, $86 \%$ of jurors who had actively participated in a trial in an electronic courtroom reported that digital visual and audio displays helped them to better understand the presented information. Moreover, $96 \%$ of these individuals reported that the use of these advanced technologies enhanced their overall ability to serve as a juror in the case (as cited in Dixon, 2012). Thus, public demand has been instrumental in precipitating the emergence of electronic courtrooms in North America; it appears that jurors in the 21 st century - who have become accustomed to interactive digital communication in their daily lives - expect an equally progressive experience in court.

The integration of technology into North American courtrooms is not without controversy. Trial lawyers - who are increasingly searching for ways to present evidence to jurors in a highly compelling manner - now have access to countless resources, presenting novel challenges to the criminal justice system and its procedures. Existing models of juror decisionmaking have not yet evolved to account for how technology may impact the way that jurors attend to and make decisions about case evidence at trial, and it remains unknown if the use of these digital technologies enhances or hinders jurors' comprehension of evidence and trial information. Given the highly persuasive nature of many of these technologies, it is possible that the use of digital modalities may encourage jurors to process information in a more superficial way, rather than focusing on the content of the information. Additionally, because jurors may have to expend very little cognitive effort to organize or evaluate evidence presented in a multimedia format, they may be less likely to critically evaluate the information. It is therefore crucial to understand the effects these novel multimedia displays are having on jurors and their decision-making processes. 
Computer-generated evidence. Among the most notable innovations in this new digital landscape are computer-generated animations and simulations, which are digital visual productions that purport to represent the operation of some scientific principle or the recreation of events at issue in a case (Wiggins, 2004). Animations are generally used to illustrate a witness's testimony of the events that occurred during the proximal time period of a crime (Fiedler, 2003). Animations could, for example, depict the moments leading up to an automotive collision in an injury case, or a police officer's actions before shooting an unarmed suspect in a wrongful death suit. Computer-generated animations give jurors an enhanced perspective of a difficult concept or a scene that would not be feasible given the limitations of traditional methods, such as photographs or oral testimony (Wiggins, 2004).

Although visual demonstrative evidence has long been used in trial settings to illustrate the oral testimony of eyewitnesses and experts, it has been said that an effective animation could reasonably convey much more information to the jury than a verbal description or a still rendition alone (Wiggins, 2004). Research has shown that dynamic visual evidence, such as that presented in an animation, can encourage greater retention of information, as well as elicit stronger emotional responses from jurors (Bell \& Loftus, 1985). Given the advances in courtroom technologies in recent years, and the proposed beneficial effects of animated evidence, it is not surprising that computer-generated animations are being introduced into court with increasing regularity (Norris, 2015). Below are a few notable real-world examples of the use of computer-generated evidence in both civil and criminal cases:

In the State v. Phillips “Out of Control Driver" (2004) case, a defendant driver was driving, and crossed the center line, left the road and crashed into a telephone pole, critically injuring one passenger and killing another. The defendant claimed he was driving only $60 \mathrm{mph}$ 
when he saw a deer enter the road, causing him to abruptly swerve left, ultimately causing the accident. Over the defendant's objection, the trial court allowed the State to admit a computergenerated reconstruction of the accident into evidence. Using information gathered from the scene of the accident (e.g., tire marks, impact on pole, approximate rate of speed), an expert created a simulation of the accident and concluded that the vehicle would have had to been traveling at least $80 \mathrm{mph}$, and that the accident resulted when the defendant's excessive speed rendered him unable to navigate the sweeping curve. Ultimately, the driver was convicted of vehicular homicide and vehicular assault.

In August of 1985, Delta Flight 191 crashed after travelling through a violent storm system, ultimately killing 137 people. In the subsequent trial, Connors v. United States (1991) both sides used computer-generated animations to illustrate highly technical and complex testimony addressing issues such as the acceleration, pitch, roll and heading of the airplane leading up to the crash. The parties' heavy reliance on computer-generated evidence and other demonstrative exhibits was unprecedented at the time; it has been widely reported that the use of the computer-generated evidence was pivotal in establishing that the Federal Aviation Administration had provided the pilots with ample warning to avoid attempting the dangerous landing that caused the fatal crash.

In the State v. Mulligan (1997) case, a prosecutor used an animation to prove that a defendant was guilty of murdering his wife on a hunting trip. The defendant had claimed that his wife tripped over a log, accidentally dropping the gun and having it discharge into her chest. Survey data from the crime scene was used to inform the creation of an animation, which ultimately showed that the victim could not have been killed in any other manner than having the rifle pointed directly at her chest and being shot at close range by her husband. 
Admissibility regulations for computer-generated evidence. At present, animated evidence is subject to the same conditions as any other visual material at trial, and so is most often classified as 'demonstrative evidence,' which comprises all evidence apart from tangible items which played a role in the crime (Legate, 2004). Examples of demonstrative evidence include the following: a map to establish a geographical feature, summary charts, photographs, diagrams, or a 3-D model of the crime scene (DeSario, 2002). It is important to note that demonstrative evidence, then, is used as a testimonial aid, and is not original evidence of the facts at issue in a crime. In comparison to original evidence, which is generally found at the crime scene and has tangible physical qualities (e.g., bullet casings, DNA and fingerprints), demonstrative evidence provides indirect impressions of what occurred, and can be used to illustrate the testimony of a witness (Legate, 2004; Dahir, 2011). Original evidence possesses inherent substantive value, whereas demonstrative evidence is more often used for illustrative purposes.

Accordingly, demonstrative evidence is generally more readily accepted by the courts (Dahir, 2011). In Canada and the U.S., demonstrative evidence is most often exempt from the rigorous evidentiary regulations governing the admissibility of original evidence and is not required to establish its scientific accuracy against the Daubert (Daubert v. Merrell Dow Pharmaceuticals, 1993) or Frye standards (Frye v. United States, 1923) in the U.S., or Mohan criteria in Canada ( $R$ vs Mohan, 1994). Provided that demonstrative evidence is deemed by a judge as relevant, an accurate representation of the facts, fair and absent of any intention to mislead, and produced from a reliable source, it should technically be considered admissible (Legate, 2004).

In recent years, however, legal scholars have increasingly struggled to distinguish 
between demonstrative evidence used for illustrative versus substantive purposes (Dahir, 2011). While in most cases demonstrative evidence is considered illustrative, in that it acts as an instructional vehicle to illustrate or summarize information to a jury, when the evidence possesses inherent probative value (i.e., the evidence may be helpful in proving facts at issue in a case) it can appropriately be defined as substantive. In instances where the demonstrative evidence is substantive, some scholars (e.g., Dahir, 2011; Legate, 2004) have argued that this type of evidence is more comparable to original evidence, and so should be subjected to the rigid admissibility criteria that are associated with original evidence. These criteria include concerns regarding the relevancy, materiality and authenticity of the original evidence.

The issue of evidence admissibility becomes further complicated when considering computer-generated evidence. According to Legate (2004), lawmakers increasingly struggle to define the nature of computer-generated evidence as either illustrative or substantive, which has led to a confusing array of rulings and a lack of predictability in the acceptance of evidence and its ultimate use at trial. As with demonstrative evidence generally, the basic predicate for admissibility of an animation is that it is a fair and accurate representation of the factual situation observed by a witness. The evidence does not claim to be a scientific recreation of an actual event, but rather an easily comprehensible depiction of a witness' story (Campbell, Jones \& Datny, 2013). Although computer-generated evidence is most often admitted into court as illustrative evidence, some courts are beginning to consider animations as substantive, based on their perceived probative value (Dahir, 2011). A computer-generated simulation, for example, does not merely illustrate testimony, but creates new evidence using mathematical calculations and testimony (Louie, Rincon, Anderson \& Kayfetz, 2007). A simulation can be used to prove a fact at issue in the case, such as exposing a mechanical failure within an aircraft's engine that 
caused it to crash, or to establish that a defendant could not have fired the shots that killed the victim, based on the angle and trajectory of the bullets found at the scene. Because simulations are created using scientific technology, there is reason to consider subjecting them to verification under the relevant standard of admission for scientific evidence.

As it stands, the classification and use of computer-generated evidence is variable at best. One of the sole criteria guiding judges' consideration of computer-generated animations is the U.S. Federal Rule of Evidence 403 (i.e., the 'balancing test'), which allows judges broad discretion to exclude relevant visual evidence "if its probative value is substantially outweighed by the danger of unfair prejudice, confusion of the issues, or misleading the jury" (Federal Rules of Evidence, 2009). Yet, without a reliable understanding of the effects of visual technologies, both on the jury and on the trial process itself, judges may be unable to accurately estimate the potential probative or prejudicial effects of this form of visual evidence. Below are a few cases which illustrate the variability in the consideration and use of computer-generated animations in real-life cases:

The case of People v. McHugh (1984), involved one of the first uses of a computergenerated simulation in a criminal trial. The defendant was driving his vehicle in New York City when he was alleged to have left the road, killing several people. The Defense hired a specialist in accident reconstruction to create a simple simulation illustrating the Defense's theory of the inclement weather conditions that caused the path the vehicle took when leaving the road. The court reviewed the evidence, determining the evidence was demonstrative in nature, and was more akin to a chart or diagram than of scientific evidence, and thus subject to a less rigorous criteria before admission.

In the case of Commonwealth v. Serge (2006), a defendant appealed his conviction for 
murder after the prosecution presented a computer-generated animation based on their theory of the case. In this case, the court decided that because the animation was a graphical illustration of the expert witness's testimony rather than a simulation based on technical calculations, the animation would not be subject to the rigorous admissibility criteria for scientific evidence, as defined by Frye v. United States (1923). Hence, the animation was deemed to have been acceptable to show in court, and the conviction of the defendant was upheld.

One the most highly publicized uses of a computer animation during trial occurred in California, in the case of People v. Mitchell (1992). At trial, the defendant claimed he killed his brother in self-defence. A forensics expert worked with a criminalist to create an animated reconstruction of the murder, based on the physical evidence found on scene. The animation was presented by the Prosecution to show, among other components, the trajectory of the bullets, and possible location of the victim when the shots were fired. The defendant appealed his conviction on the basis that the animation should not have been admitted as demonstrative evidence, with the Court conceding that it was erroneous to admit the reconstruction because its construction relied on inadmissible evidence. The defendant was granted a new trial.

Evidently, the use of this type of evidence in trial has preceded the development of evidentiary regulations that adequately dictate its use, and has created a grey area where the grounds for inclusion or exclusion of these exhibits is variable and undefined (Legate, 2004). At present, judges are required to use their discretion on a case-by-case basis to determine if an animation should be admitted into trial, yet judges may lack the expertise to properly evaluate a sophisticated animation based on the absence of pertinent criteria to guide their decisions (Fiedler, 2003). In some cases, judges are hesitant to admit relevant computer-generated evidence when it is, in fact, entirely supported by legal principles. In others, computer-generated 
evidence which is highly probative is too liberally admitted, when it should reasonably be held to a higher standard of federal regulation (Legate, 2004). In some situations, jurors themselves may be unaware of what type of evidence they are viewing. For example, since it is not required for legal representatives to disclose whether an a demonstrative exhibit is being shown for illustrative or substantive purposes, jurors may wrongly assume that what they are being shown is a scientifically-validated recreation of events, rather than an only an opinion or version of events (Selbak, 1994).

Like other types of visual evidence, the admissibility of computer-generated evidence should be standardized as much as possible; the development of well-defined and validated regulations should help ensure this evidence is being processed reliably across settings.

Regulations which pertain specifically to animations may be a valuable resource to educate legal professionals on how to properly evaluate this novel form of evidence and develop it in accordance with federal regulations (Fiedler, 2003). In order to adequately define these regulations, it is vital to understand the effects these computer-generated animations are having on jurors.

\section{Cognitive Processing of Visual Evidence}

Much of the controversy surrounding legal animations has to do with a lack of consensus as to whether animations are facilitative or prejudicial to a juror's decision-making processes. Cognitive psychological research regarding learning, memory, and persuasion can be used to draw inferences about the potential for computer-generated evidence to enhance or bias jurors' cognitive processing of case evidence and subsequent decisions. With reference to established models of juror decision-making, the following section will consider computer-generated animations within a cognitive psychological framework. 
Facilitative effects. The presumed effectiveness of visually dynamic demonstrative evidence is theoretically supported with cognitive and social psychological research regarding the positive effects of vivid information on attention, memory and comprehension.

Attention. The ability for jurors to interact with evidence is thought to increase levels of engagement, which may potentially lead to jurors evaluating the evidence more thoroughly. Recent changes to courtroom procedure in some jurisdictions (i.e., affording jurors the opportunity to take notes during trial, ask questions of witnesses, and discuss evidence amongst themselves prior to deliberation), are aimed at making jurors more active and engaged during trial, in the hopes of encouraging better decision-making (Wiggins, 2004). Research has demonstrated that vivid information (defined as being emotionally interesting, concrete and image-provoking and proximate in a sensory, temporal or spatial way) has the ability to influence jurors more than pallid information (Bell \& Loftus, 1985). Research by Paivio (1966) has demonstrated that imagery-provoking stimuli (e.g., concrete vs. abstract words and pictures vs. words) are more memorable than stimuli low in imagery, and research on visual attention has identified both colour (e.g., Wolfe \& Horowitz, 2004) and motion (for a review, see Wetzel, Radtke and Stern, 1994) as visual features that attract attention. Animations - which feature both colour and motion - may effectively maximize jurors' attention span, thereby increasing engagement and encouraging better and more informed decision-making.

Memory. Although humans learn in a variety of ways, the dual-coding hypothesis predicts that individuals understand and retain information best when it is explained verbally and with images (Clark \& Paivio, 1991; Paivio, 1969; 1971; 1986). According to this hypothesis, a dual visual and verbal representation of information facilitates learning, as the different representations of content offer additional retrieval cues during recall, resulting in reduced 
cognitive load and enhanced narrative processing. In effect, when an explanation is presented in words (i.e., narration) a learner stores this information in memory. When visual representations (i.e., static pictures or an animation) are added, this allows an opportunity for learners to select the information delivery route they prefer, resulting in an enhanced memory for the content compared to a single medium of presentation (Mayer \& Moreno, 2002). In a classic study by Weiss and McGrath (1963), after a 72 hour delay participants retained only $10 \%$ of oral information that they had heard, and $20 \%$ of visual information they had seen; when information was delivered simultaneously through both means, however, their retention of the information increased to $65 \%$. Moreover, studies of visual demonstrative evidence in forensic settings (e.g., Cooper, 1998; Selback, 1994; Vinson \& Davis, 1993) have rendered similar results, and offer empirical support to the memory enhancing qualities of dually-coded information.

Furthermore, vivid information is thought to be more efficiently retrieved from memory than pallid information (Bell \& Loftus, 1985). Accordingly, visually dynamic evidence may prove to be more effective than existing static aids or oral testimony (Nemeth, 2011). Research by Park and Feigenson (2013) explored the effects of lawyer's use of visual demonstrative evidence (i.e., PowerPoint ${ }^{\circledR}$ ) on liability judgments in a case involving statistical evidence. Results of this study found that each party's use of PowerPoint ${ }^{\circledR}$ increased participants' recall of that party's evidence, which in turn increased the defendant's judged responsibility (when plaintiffs used PowerPoint ${ }^{\circledR}$ ) or reduced it (when defendants used PowerPoint $\AA$ ). In a study by Dunn, Salovey and Feigenson (2006), when mock jurors were exposed to a dynamic animated recreation of a plane crash, they were better able to visualize and recall details of this crash than when a diagram was used, which subsequently affected their case judgments. Results of these studies indicate that dynamic visual displays may enhance jurors' recall of evidence, and that the 
use of visual technology to display evidence could reasonably maximize this effect.

Learning. Cognitive theories of multimedia learning posit that meaningful learning occurs when individuals have the opportunity to mentally construct coherent knowledge representations from material they are provided with (Mayer \& Moreno, 2002). This theory of multimedia learning is based on three assumptions derived from cognitive research: first, individuals have separate channels for processing visual information and auditory information; second, individuals have a limited capacity to process information in each channel; and third, meaningful learning occurs when individuals process information actively, such that individuals select relevant material, organize it into a coherent representation and integrate it with existing knowledge (Mayer \& Moreno, 2002). The use of charts and diagrams has, in fact, been shown to increase juror's comprehension of difficult quantitative information, and animations are hypothesized to improve juror's grasp of dynamic processes, especially when animations are accompanied by oral narration (Mayer \& Sims, 1994).

A number of influential studies on the effects of multimedia and learning have found that - under certain circumstances - dynamic animated presentation are superior to static picture presentations in terms of knowledge of specific facts, performance on specific tasks, and learning concepts (Allen \& Weintraub, 1968; Blake, 1977; Frey \& Adesman, 1976; and Konoske \& Ellis, 1986; Mayer \& Moreno, 2002). In the past few decades, studies of the effects of animations in educational settings have found that they promote incidental (e.g., Rieber, 1991), mathematical (e.g., Moreno \& Mayer, 1999) and procedural learning (e.g., ChanLin, 2000), especially when they are used in a way that aligns with how individuals cognitively process information (Mayer $\&$ Moreno, 2002). In a meta-analytic review yielding 76 pair-wise comparisons of dynamic and static imagery, Höffler and Leutner (2007) found a medium-sized overall advantage of 
instructional animations over static pictures. These studies, albeit from different disciplines, provide compelling evidence about the facilitative effects of multimedia learning, and inform our understanding of how visually dynamic demonstrative evidence (e.g. PowerPoints, animations, and other presentation software) may appeal to jurors in electronic courtrooms.

Prejudicial effects. Although cognitive research indicates that dynamic visual evidence should theoretically enhance legal judgment, jurors may use visuals in a way that biases their processing of a visual's content. In fact, concerns have been raised that the vivid qualities of computer-generated displays may actually impair a juror's ability to make impartial decisions about a defendant's culpability, and that the use of computer-generated animations may hinder a defendant's right to a fair trial (Carson \& Bull, 2003).

Persuasion. Petty and Cacioppo's (1986) Elaboration Likelihood Model of Persuasion (ELM), and Chaiken and colleague's (1989) Heuristic-Systematic Model, suggest that people process information differently depending on the state they are in when they are required to make a decision. For example, when individuals possess a strong motivation and ability to understand a topic, they will activate their 'central processing system,' whereby they will expend a great deal of cognitive effort to carefully scrutinize and evaluate the presented information before making a rational decision. Conversely, when understanding of a topic and motivation is low, individuals tend to rely on cues surrounding a message rather than the message itself. This 'peripheral processing' route requires minimal effort, and relies largely on cues stored in memory, such as individuals' perceptions of the person delivering the message. As jurors must vigilantly and consciously attend to the information to make accurate decisions, the degree of comprehension a juror possesses is a good indicator of central processing.

In a meta-analytic review of 31 studies evaluating the effects of supporting information 
on attitudes, the presence of evidence was shown to produce meaningful persuasive effects on individuals (Stiff, 1986). With this being said, however, the persuasiveness of a discrete piece of evidence is not necessarily indicative of the probative value or reliability of this evidence. Legal scholars have suggested that animated evidence may be persuasive to the point of being prejudicial, such that jurors may be considerably compelled by the version of events depicted in an animation, without taking the time to thoroughly process and critically evaluate its content. Although the courts generally assume that jurors are thinking carefully and deeply about the presented evidence, there is literature demonstrating otherwise.

The ELM (Petty \& Cacioppo, 1986) predicts that when jurors are presented with complicated information that they are not motivated or able to understand, they may attend to peripheral information, such as their perception of the lawyer's preparedness or, in the case of computer-generated evidence, how credible they perceive the animation to be. It has been suggested that an overreliance on these peripheral cues may inhibit a juror's ability to comprehend discrete pieces of evidence and apply those facts to the legal criteria provided by the judge (Greene \& Ellis, 2006). In a study by Cooper, Bennett and Sukel (1996), researchers examined the effects of complexity of testimony and level of expertise of an expert witness on jurors' verdict decisions. Participants watched a videotaped civil trial and heard testimony from an expert witness who provided an opinion on whether exposure to polychlorinated biphenyls (PCBs) could have caused a plaintiff's illness. When the evidence was presented in a simple and straightforward way, jurors relied primarily on the content of the testimony, and were able to make informed decisions based on the presented evidence. When the evidence was complex, however (i.e., when it included complicated and technical scientific jargon), jurors were twice as likely to favour the expert's opinion, indicating that jurors relied on their impressions of the 
expert's credibility rather than the evidentiary content.

In addition, in a study exploring the effects of melodramatic animation in crime news, Cheng and Lo (2018) found that individuals believed news broadcasts to be more trustworthy and more credible when these broadcasts contained animated recreations of the crime than when they did not. Cheng and Lo (2012) also found that viewers were relatively unable to distinguish between the animated elements and the genuine contents in news videos (suggesting that these videos discouraged a critical evaluation of the account depicted by the animation), and focused on extraneous cues surrounding the animation rather than the animation itself. These results suggest that multimedia evidence can encourage jurors to rely on peripheral cues and base their assessments on variables - such as the visual appeal of the information - that are unrelated to the content of the information itself.

Cognitive biases. The vivid and easily comprehensible nature of these demonstrations can be linked to hypothesized models of jury decision making (Norris, 2015). The predominant theory of juror-decision making is the story model, which proposes that jurors perceive evidence in relation to their own experience, knowledge, and beliefs (Pennington \& Hastie, 1992). The story organization facilitates comprehension and enables jurors to reach a verdict. When the scenario presented in an animation is somewhat irrelevant to a juror's personal experience and knowledge, the juror is not able to situate the evidence within a narrative. According to Norris (2015), in instances where jurors lack personal knowledge or experience about how a crime unfolded, the scenario depicted in the animation may become a key reference for jurors. Since vivid information tends to receive more weight in judgments than pallid information (Bell \& Loftus, 1985), jurors may place excessive importance on the animation, believing they have fully understood the evidence when in fact they have blindly accepted one version of events. 
Although the courts generally assume that jurors are thinking carefully and deeply about the presented evidence and coming to reasoned decisions, there is literature that demonstrates otherwise. According to Kahneman (2011), human cognition is driven by two distinct modes of cognitive thought: System 1 and System 2. Dual-systems theory predicts that the way that jurors process evidence will depend on the cognitive route that jurors use to process information (Kahneman, 2011). System 1 is described as a "reflexive" or "intuitive" system, which triggers an automated mode of thought (Tay, Ryan \& Ryan, 2016). This system operates quickly and unconsciously, requiring relatively little energy or attention. System 1 is reliant on mental operations, such as cognitive biases and heuristics, and accounts for the 'gut' feeling we experience when we see something recognizable (Stanovich \& West, 2000). On the other hand, System 2 represents the analytical or deliberate side of thinking. System 2 must be consciously activated by the decision-maker, as it involves the use of logical judgments and a careful, analytical processing of information to reach a reasoned decision (Stanovich \& West, 2000). Although this system is less prone to error than System 1, it tends to operate more slowly, as it requires a great deal of cognitive effort and is susceptible to cognitive burnout (Kahneman, 2011).

In an ideal criminal justice system, jurors should use System 2 processes to evaluate evidence, as this would presumably lead to a more careful and effortful scrutiny of the information (Kahneman, 2011). Given the cognitively demanding nature of most trials, however, there is a risk that jurors will be unable to rely exclusively on System 2 thinking throughout the duration of a trial. Studies have shown that cognitively demanding tasks can result in an individuals' cognitive resources becoming temporarily depleted (Baumeister et al., 1998; Muraven \& Baumeister, 2000). Consequently, an individual may be unable to mobilize the 
resources needed to perform another System 2 activity at the same time or shortly after, and will be more likely to default to System 1 processes to evaluate the information (Kahneman, 2011).

Research has shown that even minor alterations to how information is presented may dramatically affect the way that jurors' process and understand information, and the outcome of their judgements (Gilovich, Griffin, \& Kahneman, 2002). In fact, a recent study by Rempel, Hamovitch, Zannella and Burke (2019) found that the use of a digital visual technology (i.e., PowerPoint ${ }^{\circledR}$ ) led jurors to be less careful when scrutinizing DNA evidence compared to when the same evidence was presented in written form, and consequently, compromised their ability to render informed verdict decisions in a criminal case. This finding suggests that the use of courtroom technologies, including animations, could reasonably exacerbate an individual's tendency to rely on a System 1 style of processing, leading to a compromised understanding of the case evidence, and biased verdict decisions.

Finally, the availability heuristic is a decision bias that accounts for the way in which we tend to rely more on information that is easy to recall or simpler to interpret when making judgements (Tversky \& Kahneman, 1973). Selbak (1994) proposes that animations may work on a visceral level that easily bypasses rational faculties, essentially creating a 'pseudo-memory' of an event that may or may not be real. Given the vivid and consumable nature of animations, jurors may overestimate the probability that the scenario depicted in an animation is likely to occur, simply based on the ease in which these visuals can be retrieved from our memory.

Perceptual judgments. Animations have been considered prejudicial in that they can relax critical thinking to the point where a juror's perceptual judgments are distorted (Fiedler, 2003; Dunn, Salovey \& Feigenson, 2006). As mentioned above, the story model suggests that jurors actively organize various strands of evidence and then use common sense to construct a 
plausible narrative about the events that occurred during a crime (Pennington \& Hastie, 1992). Although jurors may initially construct multiple stories to account for how a crime occurred, one version will ultimately be deemed more acceptable than others. This decision will be based on the story's coherence (i.e., the extent to which the story makes sense, is plausible, and does not contradict itself) and coverage (i.e., the extent to which the story is able to incorporate most if not all information presented at trial; Pennington \& Hastie, 1992). With regards to computergenerated evidence, lawyers are able to present a highly coherent and complete story to jurors, allowing them to visualize a realistic version of events without having to expend a great deal of cognitive resources in order to do so (Norris, 2015).

Computer-generated animations could prove powerful in this way; their ability to show rather than tell a story to jurors may relax juror's critical thinking, discouraging them from adequately considering alternative explanations (Norris, 2015). According to Schofield (2011), when viewing visual media, the cognitive default is to believe what is seen, and only later engage in the effort needed to suspend or reject belief. Because animations are usually more engaging and entertaining, there is a potential for them to decrease the mental resources of the viewer which are available for doubt.

Differential use. While electronic courtrooms promote equal access to technology for legal counsel, computer-generated animations remain largely inaccessible due to the high costs associated with their development. Although animations have become more affordable in recent years, their price can still range from $\$ 5,000$ to $\$ 50,000$ (Austin Visuals, 2018) and some parties - most often the defense - may have to forego the use of this evidence due to financial limitations (Hadley, 2009; Schofield, 2011). Research has found that visual technologies tend to have the greatest impact on jurors' culpability judgments when their use is differential; in other 
words, when only one legal party uses a dynamic visual technology to present evidence, jurors tend to be especially punitive toward the party who presented their argument with less advanced means (e.g., Dunn, Salovey \& Feigenson, 2006; Kassin \& Dunn, 1997; Park \& Feigenson, 2013;). In criminal cases, the prosecution, who have the state's resources at their disposal, are more likely to be able to afford an animation to argue a case against the defendant. For this reason, the Defense may be at a disadvantage to defend their client's innocence against this potent form of evidence, and defendants with restricted budgets may be compelled to settle their case with a plea deal rather than take their chances against better-equipped opponents (Selbak, 1994).

In conclusion, while digital animations have arguably made it easier to explain certain aspects of a case to jurors, they have also made it easier to mislead and confuse jurors, further challenging the roles of both the trial lawyers and the judge in an adversarial system. Nonetheless, the potential for enhanced attention, comprehension, and persuasiveness make the use of computer-animated evidence appealing to many trial lawyers (Nemeth, 2011).

\section{Controlled Experimental Studies on Computer-Generated Animations}

Despite efforts to document courtroom technology generally, and to instruct judges and lawyers about its use, there have been only a handful of experimental studies which have evaluated the effects of computer-generated animations in legal settings and among those, results have been inconclusive — some have shown that animations affect jurors' judgments of culpability, while others have not. Furthermore, some studies have found that high-tech computer-generated animations differentially affect juror's understanding compared to more traditional demonstrative evidence, whereas others have failed to find this effect.

One of the first and most influential experimental studies exploring the impact of 
computer-generated animated displays was conducted by Kassin and Dunn (1997). Researchers used an animation of a slip-and-fall accident to test the hypothesis that, depending on the way they are presented, animations have the ability to either facilitate or prejudice jurors' understanding of case evidence and subsequent judgments. Participants watched a trial video involving a dispute about whether a man who fell to his death from a tall building had accidentally slipped (i.e., the plaintiff's argument) or jumped in a suicide (i.e., the defendant's argument). Participants were presented with either a pro-plaintiff version of the case (in which the body was found 5-10 feet away - a distance indicating he had slipped and fell) or a prodefendant version of the case (in which the body was found 15-20 feet away - indicating he had intentionally jumped). Within each condition, the testimony was presented either orally or with a computer-generated animation. When participants viewed the evidence within a computergenerated animation, they rendered verdicts which were more in line with the physical evidence than those who only heard the oral testimony (i.e., those in the pro-plaintiff condition rendered more pro-plaintiff judgments than those who heard only oral testimony; those in the prodefendant condition rendered more pro-defendant judgments than those who heard only oral testimony).

In a second experiment, researchers presented these animations in a suggestive way that contradicted the physical evidence. For example, in the pro-defendant version, despite the victim's body being found only 5-10 feet away from the building, the victim was shown taking a running jump off of the building; in the pro-plaintiff version, the victim was shown slipping and falling, despite his body being found 15-20 feet from the building. When the animation was presented suggestively, jurors rendered judgments which contradicted the physical evidence, and instead lent support to the opposing party's partisan theories. Hence, animations were found to 
have a stronger impact on jurors' verdicts than oral testimony alone, but whether an animation is helpful or hindering to a juror's understanding of the evidence depends on the manner of presentation and its congruence with other case evidence.

In a later study by Bennett, Leibman and Fetter (1999), researchers scripted, produced and videotaped two separate versions of an injury lawsuit to determine whether the use of a virtual simulation by the plaintiff in a motor vehicle accident would motivate jurors to apportion a greater percentage of fault and higher dollar damage. In the experimental condition, the plaintiff's expert witness presented critical evidence to the jury using an animated simulation; in the control condition, the same expert presented his opinion using only oral testimony and an aerial photograph. Contrary to the researchers' hypotheses, the use of a computer-generated simulation did not significantly influence participant's apportionment of damage or damage awards. These findings diverge with the earlier results of Kassin and Dunn (1997) and suggest that animations might not necessarily be a 'silver bullet' in trial, as some have proposed. The results of this study demonstrate that the use of animations could be superfluous in instances when jurors have ample pre-existing knowledge about the facts in the case.

Dunn, Salovey and Feigenson (2006) later investigated whether juror familiarity with the scenario presented in an animation can mediate the impact of animations on juror verdicts. In a series of experiments, researchers manipulated evidence modality (diagram vs. animation) and presentation (plaintiff vs. defendant) in two scenarios: a plane crash and an automobile collision. The use of an animation only affected jurors' verdicts in the plane crash scenario, and there were no differences in verdicts for the car crash case. Researchers attribute these findings to a mediating effect of familiarity; when an animation depicts a scenario with which participants are familiar, the information provided by the animation may become superfluous, and counteract the 
animation's persuasive effect. However, if an animation depicts a scenario that the juror is unfamiliar with, it can persuade jurors to render a verdict in favour of the side presenting the display.

Moreover, although the previous study demonstrated an effect of familiarity on mock jurors' verdicts, participants in this study proved to be poor judges of the effects of these animations on their decisions. When participants were asked about the degree to which the animations affected their verdicts, there was a negative correlation between self-reported persuasion and actual persuasion; specifically, jurors who were persuaded by the animated evidence rated animations low on self-reported importance to their decisions, and those who were not persuaded by the animated evidence reported them as high in self-reported importance. Research by Selbak (1994) found a similar effect, demonstrating jurors' expectations about the persuasiveness of computer-generated animations to be at odds with the actual influence of the evidence on their verdicts.

Norris and Reeves (2012) examined whether certain contextual factors within a computer-generated animation (i.e., colour and make of a vehicle) are capable of exerting undue prejudice on jurors. In the first of two experiments, researchers modelled a traffic accident using two distinct makes of vehicles (a Range Rover and a Volkswagen Touran) and presented them in a black-and-white animation, to test whether the make of a vehicle could influence participants' judgments of culpability or estimates of speed. When presented in a monochromatic format, the Range Rover was deemed as being more culpable for the crime than the Volkswagen Touran; however, no significant differences emerged with regard to participants' estimates of the speed of either vehicle. In the second experiment, researchers used a 2 (vehicle colour: beige vs. red) $\mathrm{x}$ 2 (vehicle make: Range Rover vs. Volkwagen Touran) between-subjects design, to test whether 
the colour of the vehicle could influence participants' judgments of culpability and speed. In this experiment, when the animation was presented in full colour, the Range Rover was, again, judged to be the most culpable, regardless of whether it was red or beige. There were no significant differences in estimates of vehicle speed, indicating that the higher observed culpability judgements in the Range Rover condition were not mediated by participants' estimates of speed. These findings cast doubt on the facilitation hypothesis, and demonstrate that seemingly negligible contextual features of an animation can unduly sway jurors' culpability decisions.

Related work by Norris (2013) explored the influence of angle of presentation of an animated sequence, assessing both estimations of vehicle speed and overall culpability in a twovehicle accident. When jurors in the study were presented with an animation depicting a twovehicle vehicular collision, the three viewpoints presented (overhead, facing and internal) had a significant impact upon judgements. For the forward-facing animation, $92 \%$ attributed the cause of the accident to Car 1, and $8 \%$ to Car 2. Conversely, in the internal view animation, only $34 \%$ made this judgement, with the remaining $66 \%$ attributing blame to Car 2. For the overhead view, the percentiles were $43 \%$ for Car 1 and $57 \%$ for Car 2. These results indicate that judgements of culpability can be manipulated depending upon the angle at which an animation is presented, and suggest that even vantage point should be considered as a potential source of bias to jurors' judgments in legal contexts.

In summary, the extant research investigating the effects of computer-generated animations has only skimmed the surface in terms of understanding how this complex form of evidence influences jurors. As it stands, the results of these studies are mixed - some have demonstrated that computer-generated animations can affect jurors above and beyond traditional 
forms of evidence, while others have failed to find this effect. Given the small sample of studies that have been conducted, many of which have methodological limitations, such as limited sample sizes, homogenous participants, and a lack of external validity, it would be premature to expect any clear patterns to emerge under these circumstances (Carson \& Bull, 2003; Feigenson, 2010). Despite initial studies having failed to establish animations as accepted courtroom tools, these early investigations do represent a promising start for this new research area, and provide a solid foundation for future lines of inquiry.

\section{Summary}

Although evidentiary misconduct has previously been linked to wrongful convictions, relatively little has been done to understand and regulate novel forms of evidence, particularly computer-generated animations. Instead, computer-generated animations are being permitted into court with increasing regularity, on the grounds that they aid juror understanding (Wiggins, 2004; Norris, 2015). Although animations are generally subject to the same regulations as other demonstrative evidence, there is evidence to suggest that animations are fundamentally different from other types of visual aids and have the potential to significantly bias jurors' decisions at trial. In Canada and the United States, federal evidentiary regulations dictate that the probative value of demonstrative evidence must substantially outweigh the prejudicial effects for evidence to be admitted (Federal Rules of Evidence, 2009). As such, further empirical research in this area is needed to develop an understanding of the potential for this type of evidence to facilitate or prejudice jurors' decisions at trial.

The current study expanded on research by Kassin and Dunn (1997), which demonstrated that animations have a greater impact on jurors' verdicts than oral testimony, either facilitating or prejudicing jurors' verdict decisions depending on the context of their presentation. These 
findings by Kassin and Dunn (1997) are consequential, and provided the current study with a theoretical and methodological framework by which we could further explore the persuasive effects of computer-generated animations. Technology has advanced considerably since the study was originally conducted, and computer-generated animations have undergone a marked increase in realism and complexity. For this reason, modern day computer-generated animations may reasonably exert a greater influence on jurors than the materials used in the original study. It was therefore necessary to investigate whether Kassin and Dunn's (1997) results could be replicated using updated digital materials and a novel criminal case narrative. Using a graphically advanced computer-generated animation, the current study investigated whether presentation modality and evidence congruence affect juror's ability to properly evaluate evidence and render informed verdicts in a second-degree murder case.

\section{Purpose and Hypotheses}

The goal of the current study was to enrich the current literature on computer-generated animations in legal settings, further explicating the conditions under which animations are facilitative or prejudicial to jurors' understanding of case information. Based on previous findings by Kassin and Dunn (1997), the study had two primary hypotheses: First, a main effect of congruence, such that participants who heard a defendant's testimony which was congruent with the majority of other case evidence would be more likely to render 'not-guilty' verdicts than those who heard testimony which was incongruent with other case evidence. Second, a main effect of modality, such that participants who viewed a computer-generated animation supporting the defendant's testimony would be more likely to render 'not-guilty' verdicts than those who viewed a static visual aid in support of the testimony as well as those who did not view any aid.

The hypotheses of this study corresponded with Kassin and Dunn's (1997) facilitation 
and prejudice hypotheses. Specifically, if the presence of a computer-generated animation increases the likelihood of participants' rendering 'not-guilty' verdicts across congruence conditions, the study will have provided evidence that a computer-generated animation is facilitating participants' decisions in the congruent condition (i.e., aligning the verdicts with other case evidence) as well as prejudicing participants' decisions in the incongruent condition (i.e., distorting participants verdicts away from other case evidence).

\section{Method}

\section{Participants}

A power analysis was conducted using $\mathrm{G}^{*}$ Power to determine the number of participants required for the study to obtain $80 \%$ power for a logistic regression analysis when the effect size is between small and medium (Odds Ratio = 2.3) and with one dichotomous dependent variable. Results indicated that 196 participants were needed for sufficient power. Participants were recruited through Ryerson University's Psychology research participant pool and were compensated 1\% toward their Introductory Psychology course grade for their participation. A total of 240 undergraduate students were recruited, but the final sample contained 238 undergraduate students ( $84.0 \%$ women, $14.3 \%$ men, $0.4 \%$ non-binary) due to two participants failing an attention check. Ages ranged from 17 to $53(M=19.50, S D=3.81)$. The sample was predominantly White (35.7\%), with $15.5 \%$ identifying as South Asian, $13.0 \%$ as Filipino, $8.0 \%$ as Chinese, $4.6 \%$ as Southeast Asian, 3.8\% as Black, and the remainder identifying as Arab (1.7\%), Indigenous (0.4\%), Japanese (0.4\%), Korean (2.1\%), Latin American (2.1\%), West Asian $(2.1 \%)$, or 'Other' (7.6\%). A subset of participants $(2.1 \%)$ chose not to report their ethnicity. 


\section{Design}

The study was a 2 (congruence of testimony: incongruent vs. congruent) x 3 (modality of testimony: no-aid vs. static visual aid vs. computer-generated animation) between-subjects design with one dichotomous dependent variable (i.e., verdict: guilty or not-guilty) and two exploratory continuous dependent variables (i.e., confidence in verdict, and probability of guilt estimate). Participants were randomly assigned to one of six conditions: 1) congruent testimony, no-aid, 2) congruent testimony, static visual aid, 3) congruent testimony, computer-generated animation, 4) incongruent testimony, no-aid, 5) incongruent testimony, static visual aid, 6) incongruent testimony, computer-generated animation.

\section{Materials}

Transcripts. Participants read a trial transcript featuring a police officer who was on trial for murder after shooting and killing a civilian. This transcript was based on a real civil case, Avery Cody Sr., et al. v. County of Los Angeles (2010), which pertained to the alleged wrongful death of a 16-year-old victim in Compton, California in 2009. Details of the wrongful death lawsuit were integrated with confabulated details to create the narrative of a criminal case, in which the defendant was being indicted on second-degree murder charges. Each transcript included the indictment, opening statements from the Prosecution and the Defense, the testimony of eight witnesses for the prosecution and the defense, cross-examination by either party, as well as closing statements. Although each transcript featured the same eight witnesses in the same order, testimony of two of the eight witnesses (Laura Lee and Dr. David Lawrence) differed depending on congruence condition, lending greater support to either the prosecution or the defense's case.

Pro-Defense transcript. The Pro-Defense transcript included the testimony of five 
witnesses for the Defense, and three for the Prosecution (see Appendix A for witness details). The following witnesses testified for the defense in the Pro-Defense transcript:

Laura Lee. Laura Lee is the paramedic who arrives on scene to help the victim. Her testimony serves as a character reference for the defendant. She describes Officer Gary Green as being concerned about the victim, performing CPR on the victim, and mentions that she noticed a gun on the victim's person.

Dr. David Lawrence. Dr. David Lawrence is the forensic pathologist. His testimony explains that the victim's wounds reveal that his body was turned to face the officer, his arm extended in a way that suggests he was pointing his own gun at the defendant at the time he was shot. He goes on to explain that the victim's wounds suggest that he was at least 20-25 feet away from the defendant - a fact that supports the defendant's claim that the victim was fleeing the scene.

Gary Green. Gary Green is the defendant in the case. His testimony was presented orally, with the accompaniment of one of the following: no-aid, static visual aid, or computer-generated animation. The defendant explains that the victim and his friend group were uncooperative, and that the victim fled and was trying to shoot at him. Gary Green expresses remorse about the situation, and explains that was acting in self-defence and did not mean to intentionally kill the victim.

Simon Callaghan. Simon Callaghan is Gary Green's patrol partner. He serves as a character witness for the defendant, and corroborates the defendant's testimony.

Lucinda Armstrong. Lucinda Armstrong is the victim's school counsellor. Lucinda's testimony serves to defame the victim's character. She explains the victim's former behavioural problems, his numerous suspensions, and possible gang involvement. 
Pro- Prosecution transcript. The Pro-Prosecution transcript included the testimony of five witnesses for the Prosecution, and three for the Defense. The following witnesses testified for the prosecution in the Pro-Prosecution transcript:

Jamal Williams. Jamal Williams is the victim's best friend, who was on scene at the time of the shooting. Jamal serves as a character reference for the victim, and discredits Gary Green by contradicting his testimony. Specifically, Jamal denies that the victim was running from Gary Green or failing to cooperate with him. He also mentions that the victim was in close proximity to the officer at the time of the shooting, indicating that Gary Green's testimony is false, and that he shot the victim with the intent to kill.

Ray Young. Ray Young is an eyewitness to the crime. Ray Young testifies that the victim and his friend group were highly cooperative with officers, that the victim did not attempt to flee the scene, and that he was shot in much closer proximity than the defendant described.

Patrick Simms. Patrick Simms is the Chief of Police Training in the County of Los Angeles. He testifies that Gary Green had been trained in de-escalation techniques, and that this particular situation did not warrant the use of deadly force that was used by the defendant.

Laura Lee. Laura Lee is the paramedic who arrives on scene to help the victim. Her testimony serves to discredit the defendant. She describes Officer Gary Green as being unconcerned about the victim, failing to perform CPR on the victim, and mentions that she noticed an iPhone beside the victim's person - not a gun.

Dr. David Lawrence. Dr. David Lawrence is the forensic pathologist. His testimony explains that the victim's wounds suggest that he was shot directly in the back, as if he was walking away from the defendant at the time he was shot. He discredits Gary Green's testimony 
by explaining that the victim could have only been 5-10 feet away from the defendant - a fact that implies that he was not running or fleeing the scene as the defendant claimed

Testimonial evidence. In addition to reading the trial transcript, all participants listened to oral testimony from the defendant (Gary Green). Depending on condition, this oral testimony was delivered in conjunction with either a static visual aid, a computer-generated animation, or without an additional aid. The dichotomous nature of the case transcripts (i.e., Pro-Defense or Pro-Prosecution) and the fixed nature of the defendant's testimony (i.e., always Pro-Defense) created a disparity in terms of evidence congruence, such that half of the participants were presented with congruent evidence (i.e., both the defendant's testimony and the trial transcript were Pro-Defense), whereas the other half of participants were presented with incongruent evidence (i.e., although the defendant's testimony was Pro-Defense, the transcript was ProProsecution). In all conditions, the presentation of the defendant's testimony, with or without visual aids, spanned a total of 3 minutes and 6 seconds.

No-aid condition. Participants heard the oral testimony of the defendant in the trial, Officer Gary Green, who described the events that occurred during the proximal period between the victim and four friends being confronted by officers outside of a donut shop, and when the victim fled and was shot (see Appendix B). Participants listened to this testimony while viewing a blank screen.

Static visual condition. Other participants heard the defendant's oral testimony in conjunction with a series of static, visual images. Participants viewed the images digitally on laptop computers, while listening to the defendant's oral testimony wearing headphones. Five still images representing the defendant's version of events were captured from the computer- 
generated animation, and were presented in a sequence coinciding with the oral testimony of the defendant (see Appendix C).

Computer-generated animation condition. In addition to the defendant's oral testimony, some participants received additional visual evidence in the form of a computer-generated animation. Participants viewed an animated video depicting the defendant's account of the crime, while listening to the defendant's oral testimony using headphones. This vivid, computergenerated animation illustrated the defendant's account of the crime as it was being narrated from multiple vantage points. At three points during the animation, the video pauses, magnifies and directs the viewers' attention to salient aspects of the crime. For example, when the defendant describes his realization that the victim was in possession of a gun, the video pauses and gradually zooms to depict the victim fleeing with a gun. The animation was originally created for use in the civil trial, Avery Cody Sr., et al. v. County of Los Angeles, by Eyewitness Animations ${ }^{\circledR}$, a company that specializes in high quality forensic animation and courtroom graphics. The animation is freely accessible for viewing and download by the public and can be found at the following link: https://vimeo.com/63442733.

Dependent measures. The study included three dependent variables: a dichotomous verdict decision (i.e., guilty or not-guilty), a continuous probability of guilt estimate (i.e., an open-ended percentage), and a continuous confidence in verdict response (i.e., a Likert scale with a range of 1-10).

Additional questionnaires. The study included five additional questionnaires which were analyzed as covariates. These scales were included for exploratory purposes, to investigate whether any additional measures significantly predicted participants' verdicts. 
Evidence Strength Individual Items. Participants completed the Evidence Strength Scale, adapted from Koehler, Schweitzer, Saks and McQuiston (2017). This scale measured participants' perceptions of each attorney, how convincing they found the defendant's testimony, and the strength of the Prosecution and Defense's cases. This scale also included three attention check questions, to ensure participants were paying attention and reading the transcript thoroughly during the study (see Appendix D).

Perceptions of Police Scale (POPS). Participants completed the Perceptions of Police Scale (Nadal \& Davidoff, 2015). Participants were asked to indicate the degree to which they agreed or disagreed with twelve items on a 5-point Likert scale ranging from Strongly Agree (1) to Strongly Disagree (5). This scale measures an individual's attitudes toward the police, with higher scores indicating more favourable attitudes toward police, and lower scores indicating less favourable attitudes toward police. This scale possesses a reliability coefficient of $\alpha=.94$ (see Appendix E). In the current study, the POPS scale also demonstrated good internal consistency $(\alpha=.91)$.

Attitudes Toward Science and Technology. Participants completed an adapted version of the Attitudes Toward Science and Technology Scale (Hans, Kaye, Dann, Farley \& Albertson, 2011). This abbreviated version of the scale assesses jurors' attitudes toward technology, based on their perceived reservations ( 3 items) or promise toward technology (4 items) using a 4-point Likert scale ranging from strongly agree (1) to strongly disagree (4) (see Appendix F). The original study by Hans, Kaye, Dunn, Farley and Albertson (2011) did not provide any information regarding the reliability of the scale. In the current study, the ATST scale demonstrated poor internal consistency $(\alpha=.51)$, and thus results derived from this scale should be interpreted with caution. 
Juror Bias Scale. Participants completed the Juror Bias Scale, (Kassin \& Wrightsman, 1983) consisting of 22 items to which participants indicate whether they agreed or disagreed with items on a 5-point Likert scale ranging from Strongly Agree (1) to Strongly Disagree (5). This scale measures biases of prospective jurors in a criminal trial, specifically, to determine if they lean toward the prosecution (e.g., express agreement on questions such as, "A suspect who runs from the police most probably committed the crime") or the defense (e.g., "The defendant is often a victim of his/her own bad reputation") This scale possesses a reliability coefficient of $\alpha=$ .64 (see Appendix G). In the current study, the juror bias scale demonstrated weak internal consistency $(\alpha=.41)$ and thus the results of this scale should be interpreted with caution.

Demographics. Participants completed a demographics questionnaire, which included questions about participants' age, gender identity and ethnic/cultural background (Appendix $\mathrm{H}$ )

\section{Procedure}

Participants were tested in the Psychology and Law Lab at Ryerson University. Written and verbal consent was obtained prior to the commencement of the study (see Appendix I). Participants were told that the purpose of the study was to evaluate how legal attitudes affect jurors' decision making in a court case, and that the study would take approximately one hour. Participants were not specifically informed that the study would be investigating the effects of visual modalities on legal judgments.

Participants were told that they were to act as mock jurors in a criminal case. Although two participants were scheduled for most sessions, they were provided with their own case materials and were directed to work independently throughout the duration of the study. Participants were first presented with a brief set of instructions which outlined their responsibilities as a juror and contained general legal information regarding the proceedings of a 
criminal trial and what to expect as a mock juror during the session (Appendix J). These preliminary instructions were intended to provide participants with baseline knowledge about the criminal justice system and orient them to basic legal terminology in order to enhance the ecological validity of the study.

Next, participants read a trial transcript involving a police officer who is on trial for second-degree murder after shooting a civilian. Participants viewed this transcript on laptop computers, in a series of 45 slides with a white background and Lucida Sans font in size 20. Participants were able to navigate through slides at their own pace and were able to reverse slides that had passed to review the information again if they chose to do so. Within the trial transcript, participants read the opening statements from the Prosecution and the Defense, and read testimony from eight eyewitnesses (including the defendant). Depending on condition, details within the transcript favoured the Prosecution's argument (i.e., Pro-Prosecution transcript: five witnesses testifying for the Prosecution and three for the Defense) or the Defense's argument (five witnesses testifying for the Defense and three for the Prosecution). After each witness was directly examined, participants also read the cross-examination from the adversarial legal attorney.

The defendant, Gary Green, was the sixth witness to take the stand in the case. Participants were instructed to use the headphones provided to listen to the defendant's oral account of what occurred during the crime. When participants were ready to listen to the defendant's testimony, they were directed to push the "play" button to begin the oral narration. Depending on condition, visual evidence corresponding with Gary Green's oral testimony story was displayed to participants in one of three modalities: a static visual aid, a computer-generated animation, or with no visual aid (participants saw a black screen). 
For participants in the congruent condition, the defendant's account of the crime was consistent with the accounts provided by the majority (5/8) of witnesses in the trial. For those in the incongruent condition, the defendant's account was inconsistent with the majority (5/8) of witnesses in the trial. After each participant received the testimony from all eight witnesses, including the defendant, participants were presented with closing remarks from the Defense and the Prosecution. At this point, jurors received a set of instructions about how to appropriately render a verdict in the case (see Appendix K). Participants were then asked to render a verdict, report their confidence in their verdict, and estimate the likelihood that the defendant is guilty of the crime of which he is accused (Appendix L).

After each participant had completed the trial transcript and rendered a verdict, they completed a set of questionnaires on Qualtrics ${ }^{\circledR}$, including the Evidence Strength Scale (Koehler, Schweitzer, Saks \& McQuiston, 2016), Attitudes Toward Science and Technology Scale (Hans, Kaye, Dann, Farley \& Albertson, 2011), the Juror Bias Scale (Kassin \& Wrightsman, 1983) as well as a demographics questionnaire. Once participants completed all tasks, they were debriefed about the true nature of the study (see Appendix M), asked to refrain from discussing the study with their peers who may participate in the future, and thanked for their participation.

\section{Results}

\section{Verdicts}

Although data was collected from 240 participants, two participants failed an attention check (by failing to correctly answer at least 3/4 multiple-choice, attention check questions) and their results were excluded from the analysis. The final sample contained 238 participants. Of these 238 participants, $161(67.6 \%)$ reported that the defendant in the case was guilty, compared 
to $77(32.4 \%)$ who reported that the defendant was not-guilty. See Table 1 for frequencies across congruence and modality conditions.

\section{Hypothesis 1: Congruence and Verdict}

We predicted a main effect of congruence, such that participants who received testimony from the defendant that was congruent (i.e., aligned) with other case evidence, would be more likely to render not-guilty verdicts than when the defendant's testimony was incongruent (i.e., disparate) with other case evidence. To test this hypothesis, we conducted a binary logistic regression with two independent variables (congruence and modality) as predictors of the dichotomous verdict variable (where 'guilty' represented the control group and 'not-guilty' represented the reference group). Results of this analysis revealed a significant main effect of congruence, such that $54.4 \%$ of participants in the congruent condition reported that the defendant was not-guilty, compared to only $12.3 \%$ of participants in the incongruent condition (see Figure 1), $B=2.35, S E=.37, p<.001, \operatorname{Exp}(B)=10.49,95 \%$ CI $[5.09,21.6]$.

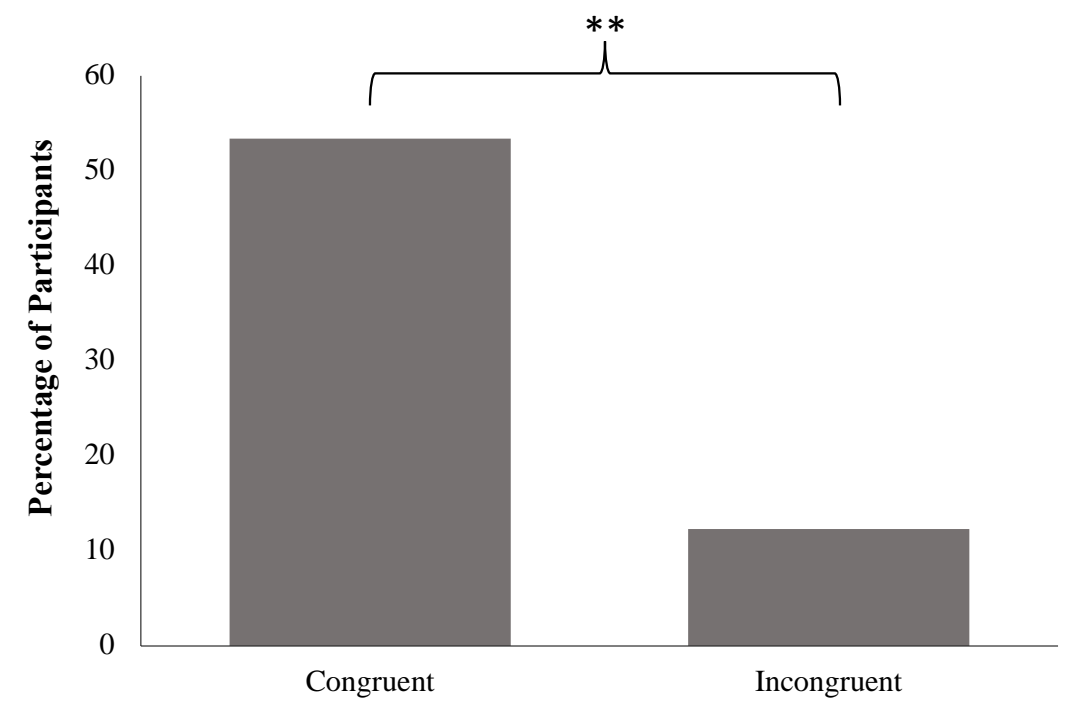

Congruence of Defendant's Testimony

Figure 1. Percentage of participants rendering a not-guilty verdict by congruence condition, $p$ $<.001$. 


\section{Hypothesis 2: Modality and Verdict}

We predicted a main effect of modality, such that participants who received the defendant's testimony with the accompaniment of a computer-generated animation would be more likely to render 'not-guilty' verdicts than those who received the testimony with no-aid, or with a static visual aid. To test this hypothesis, we conducted a binary logistic regression with a Helmert contrast to compare the mean probability of participants rendering a not-guilty verdict between 1) computer-generated animation vs. static aid and no-aid conditions, and 2) static aid vs. no-aid conditions. Results of this analysis revealed a significant main effect, such that $51.3 \%$ of participants who viewed a computer-generated animation rendered a not-guilty verdict, compared to only $22.8 \%$ across the static visual aid and no-aid conditions, $B=1.63, S E=.36, p$ $<.001, \operatorname{Exp}(\mathrm{B})=5.08,95 \% \mathrm{CI}[2.53,10.2]$. Moreover, the probability of participants rendering a not-guilty verdict did not significantly differ between the static visual aid (25\%) and no-aid $(20.5 \%)$ conditions (see Figure 2$), B=.28, S E=.42, p=.581, \operatorname{Exp}(B)=1.319,95 \%$ CI $[.58$, 2.99].

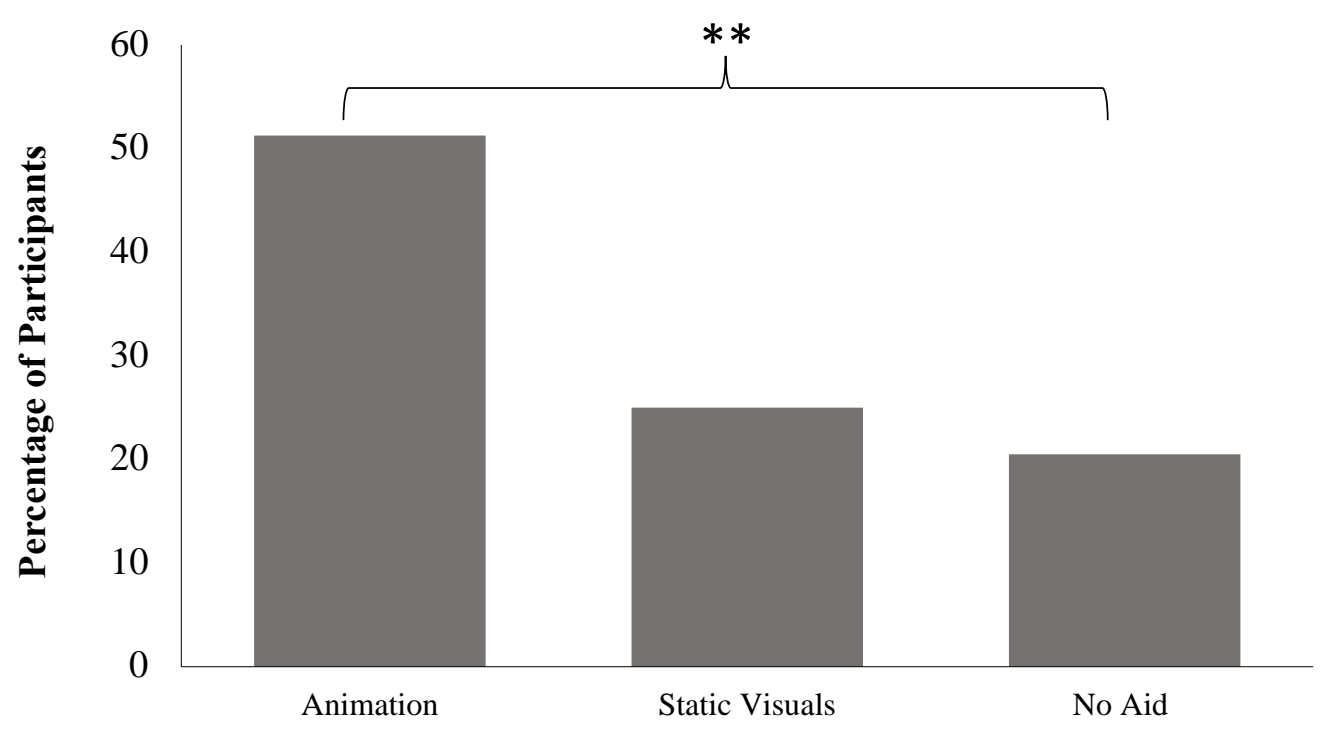

Modality of Defendant's Testimony 
Figure 2. Percentage of participants rendering a not-guilty verdict by modality condition, $p$ $<.001$.

\section{Interaction of Modality and Congruence}

For exploratory purposes, we tested whether evidence modality and congruence interacted to predict participants' verdict decisions. An interaction term was created and entered into the aforementioned binary logistic regression model; results of this analysis revealed that the interaction between evidence modality and congruence and participants' verdicts was not significant, $B=.523, S E=.51, p=.308, \operatorname{Exp}(B)=1.69,95 \%$ CI [.03, 2.93]. Consequently, the interaction term was removed from this model and the statistics reported herein are based on the model without an interaction term.

Table 1

Distribution of Verdict Decisions as a Function of Evidence Congruence and Modality

Congruence

\begin{tabular}{cccccc}
\multicolumn{2}{c}{ Incongruent } & \multicolumn{2}{c}{ Congruent } & \multicolumn{2}{c}{ Total } \\
\hline Guilty & Not & Guilty & Not & Guilty & Not \\
& Guilty & & Guilty & & Guilty
\end{tabular}

Modality

\begin{tabular}{|c|c|c|c|c|c|c|}
\hline No-aid & 40 & 1 & 22 & 15 & 62 & 16 \\
\hline Static Visuals & 38 & 3 & 22 & 17 & 60 & 20 \\
\hline Animation & 29 & 11 & 10 & 30 & 39 & 41 \\
\hline & 107 & 15 & 54 & 62 & 161 & 77 \\
\hline
\end{tabular}

Open-Ended Verdict Responses

Participants were asked to report, in their own words, why they chose their verdicts. In order to explore whether participants were cognizant of the impacts of the defendant's testimony 
on their verdict decisions, we coded these open-ended responses for any reference to the defendant's testimony as grounds for why they chose a particular verdict. Results of this analysis demonstrated that only $27.7 \%$ of participants specifically cited the defendant's testimony as a factor in their ultimate verdict decision. We explored whether evidence congruence and/or modality predicted whether participants reported, and were presumably cognizant, of the impact of the defendant's testimony on their verdict decisions. Results of a logistic regression analysis revealed participants in the no aid (30.8\%), static visual aid (25\%), and computer-generated animation conditions (27.5\%) did not significantly differ in their likelihood of acknowledging the defendant's testimony as contributing to their verdicts, $B=-.07, S E=.20, p=.725, \operatorname{Exp}(B)=$ $.93,95 \%$ CI $[.64,1.37]$. The congruence of the defendant's testimony with other case evidence, however, did affect participants' likelihood of referencing this testimony in their open-ended responses. Specifically, participants in the congruent condition mentioned the defendant's testimony at a rate of only $8.6 \%$, compared to $45.9 \%$ of participants in the incongruent condition, $B=2.20, S E=.38, p<.001, \operatorname{Exp}(B)=8.98,95 \%$ CI $[4.29,18.83]$.

\section{Covariate Predictors of Verdict}

Demographics. Participants completed a demographics questionnaire, which included questions about their age, gender identity and ethnic/cultural background. Variables for age (continuous), gender identity (categorical) and ethnic/cultural background (categorical) were entered entered into the logistic regression model to determine whether participants' demographics significantly predicted their verdict decisions (dichotomous). Results of the logistic regression analysis revealed that age did not significantly predict participants' verdicts, $B=-.13, S E=.07, p=.060, \operatorname{Exp}(B)=.878,95 \%$ CI $[.77,1.01]$ nor did gender identity, $B=-.52$, 
$S E=.50, p=.296, \operatorname{Exp}(\mathrm{B})=.60,95 \% \mathrm{CI}[.22,1.57]$ or ethnicity, $B=.01, S E=.05, p=.871$, $\operatorname{Exp}(B)=1.01,95 \%$ CI $[.92,1.11]$

Juror Bias. Total scores on the Juror Bias Scale (JBS) ranged from 34 to 62 ( $M=48.54$, $\mathrm{SD}=5.32$ ). The jury bias variable (continuous) was entered into the logistic regression model to determine whether participants' level of pro-prosecution or pro-defense bias significantly predicted their verdict decisions. Results of the logistic regression analysis revealed that participants' pro-prosecution or pro-defense bias did not significantly predict their verdicts, $B=$ $.02, S E=.03, p=.561, \operatorname{Exp}(B)=1.02,95 \%$ CI $[.95,1.09]$.

Attitudes Toward Science and Technology. Total scores on the abbreviated Attitudes Toward Science and Technology Scale (ATST) ranged from 11 to $32(\mathrm{M}=21.94, \mathrm{SD}=3.14)$. The ATST variable (continuous) was entered in the logistic regression model to determine whether participants' attitudes toward technology significantly predicted their verdict decisions. Results of the logistic regression analysis revealed that participants' attitudes toward science and technology did not significantly predict their verdicts, $B=.03, S E=.06, p=.650, \operatorname{Exp}(B) 1.03$, $95 \%$ CI $[.92,1.16]$.

Perceptions of Police. Total scores on the abbreviated Perceptions of Police Scale (POPS) ranged from 18 to $57(\mathrm{M}=37.96, \mathrm{SD}=6.47)$. The POPS variable (continuous) was entered in the logistic regression model to determine whether participants' attitudes toward police significantly predicted their verdict decisions. Results of the logistic regression analysis revealed that participants who held more favourable attitudes toward police were significantly more likely to render a not-guilty verdict in the case than those who held less favourable attitudes toward police, $B=.12, S E=.03, p<.001, \operatorname{Exp}(B) 1.13,95 \%$ CI $[1.06,1.20]$.

\section{Exploratory Analyses}


Confidence in verdict. Participants were asked to report how confident they felt about their verdicts on a scale from 1-10, with higher scores indicating greater confidence in their verdicts. We used a linear regression analysis to explore whether evidence congruence and/or modality predicted participants' confidence scores. Results of this analysis indicated a main effect of congruence, such that participants in the incongruent condition felt more confident in their verdicts than those in the congruent condition, $B=1.22, S E=.20, \beta=.37, p<.001,95 \% \mathrm{CI}$ $[.83,1.61]$ (see Table 2 for descriptives). In addition, modality significantly predicted confidence in verdict, $B=.32, S E=.12, \beta=.16, p<.05,95 \% \mathrm{CI}[-.56,-.08]$. Specifically, participants in the computer-generated animation condition were significantly less confident in their verdicts compared to those in the no-aid condition, $B=-.29, S E=.14, \beta=-.14, p<.05,95 \%$ CI $[-.57$, $.01]$, however there were no significant differences in confidence between those in the no-aid condition and the static visual condition, $B=-.05, S E=.14, \beta=-.03, p=.718,95 \%$ CI $[-.33$, .23] (see Figure 3). There was no interaction between congruence and modality on confidence in verdict, $B=-.01, S E=.25, \beta=-.00, p=.967,95 \%$ CI $[-.50, .47]$ (see Table 2 for descriptives). Notably, a t-test revealed that participants who rendered guilty verdicts $(M=8.34, S D=1.24)$ were significantly more confident in their verdicts than those who rendered not-guilty verdicts $(M=6.66, S D=1.88), t=8.19, S E=.21, p<.001,95 \% \mathrm{CI}[1.28,2.08]$. This finding helps to elucidate why individuals in the computer-generated animation condition (who were more likely to render not-guilty verdicts than the no-aid or static visual condition), also reported less confidence in their verdicts. 


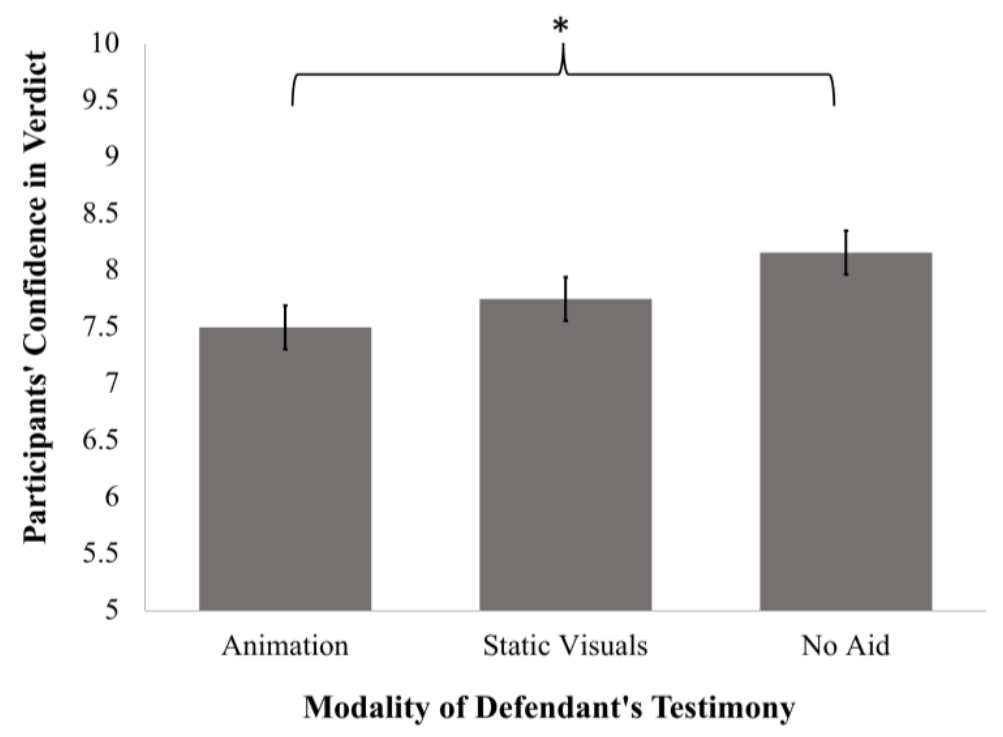

Figure 3. Participants' reported confidence in verdict by modality condition, $p<.05$.

Table 2

Confidence in Verdict as a Function of Evidence Congruence and Modality (1-10)

\begin{tabular}{|c|c|c|c|c|c|c|}
\hline & \multicolumn{4}{|c|}{ Congruence } & \multirow{2}{*}{\multicolumn{2}{|c|}{ Total }} \\
\hline & \multicolumn{2}{|c|}{ Incongruent } & \multicolumn{2}{|c|}{ Congruent } & & \\
\hline & $M$ & SD & $\mathrm{M}$ & $\mathrm{SD}$ & $\mathrm{M}$ & SD \\
\hline No-aid & 8.78 & .96 & 7.47 & 1.42 & 8.16 & 1.36 \\
\hline Static Visuals & 8.27 & 1.18 & 7.21 & 1.61 & 7.75 & 1.50 \\
\hline Animation & 8.13 & 1.71 & 6.85 & 2.14 & 7.49 & 2.03 \\
\hline & 8.40 & 1.34 & 7.17 & 1.76 & 7.80 & 1.67 \\
\hline
\end{tabular}

Probability of guilt estimates. Regardless of their verdict decision, participants were asked to report an open-ended percentage estimate (0-100\%) of the likelihood that the defendant was, in fact, guilty of second-degree murder. We used a linear regression analysis to explore whether evidence congruence and/or modality significantly predicted participants' probability of 
guilt estimates. Results of this analysis revealed a main effect of congruence, such that participants in the incongruent condition reported significantly higher probability of guilt estimates than those in the congruent condition, $B=23.41 S E=2.98, \beta=.44, p<.001,95 \% \mathrm{CI}$ $[17.53,29.30]$. Further, modality also significantly predicted participants' probability of guilt estimates, $B=-7.85, S E=1.83, \beta=-.24, p<.001,95 \%$ CI $[-11.46,-4.24]$. Specifically, participants in the computer-generated animation condition reported significantly lower probability of guilt estimates than participants in the no-aid condition, $B=-9.19, S E=-.21, \beta=-$ $.28 p<.001,95 \%$ CI [-13.33, -5.04], however there were no significant differences in probability of guilt estimates between those in the no-aid condition and the static visual condition, $B=2.71$, $S E=2.10, \beta=.08, p=.199,95 \%$ CI $[-1.44,6.85]$, see Figure 4. There was no interaction between modality and congruence on probability of guilt estimates, $B=2.03, S E=3.67, \beta=.06$, $p=.580,95 \%$ CI $[-5.20,9.27]$ (see Table 3 for descriptives). Of note, a t-test revealed that participants who rendered guilty verdicts $(M=84.81, S D=11.53)$ reported higher estimates of the defendant's probability of guilt than those who rendered not-guilty verdicts $(M=38.58, S D=$ 21.50), $t=21.58, S E=2.14, p<.001,95 \%$ CI $[42.00,50.44]$.

\section{Probability of Guilt Estimates by Modality Condition}

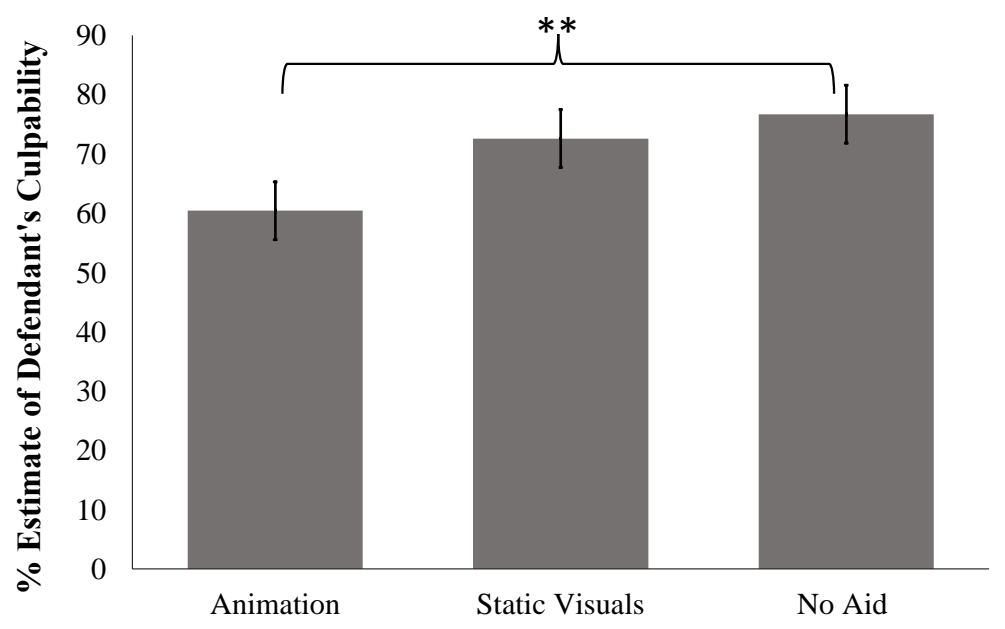

Modality of Defendant's Testimony 
Figure 4. Participants' estimates of the defendant's culpability by modality condition, $p<.001$.

Table 3

Probability of Guilt Estimates as a Function of Evidence Congruence and Modality (\%)

\begin{tabular}{|c|c|c|c|c|c|c|}
\hline \multirow{2}{*}{ Modality } & \multicolumn{4}{|c|}{ Congruence } & \multicolumn{2}{|c|}{ Total } \\
\hline & $\mathrm{M}$ & $\mathrm{SD}$ & $\mathrm{M}$ & $\mathrm{SD}$ & $\mathrm{M}$ & SD \\
\hline No-aid & 88.12 & 12.51 & 64.03 & 25.58 & 76.69 & 23.11 \\
\hline Static Visuals & 81.49 & 17.38 & 63.28 & 25.39 & 72.61 & 23.39 \\
\hline Animation & 74.40 & 25.91 & 46.45 & 27.83 & 60.43 & 30.19 \\
\hline Total & 81.39 & 19.98 & 57.72 & 27.35 & 69.85 & 26.60 \\
\hline
\end{tabular}

Perceptions of case strength. Participants were asked to report their perceptions

regarding the strength of the Defense and Prosecution's cases, on a scale ranging from 0 (Not at all Strong) to 7 (Extremely Strong). Results of a paired samples t-test revealed that, on average, participants perceived the Prosecution's case to be significantly stronger than the Defense's case, $t(231)=8.20, S D=2.41, \mathrm{p}<.001,95 \%$ CI $[.98,1.60]$ (see Table 4 for descriptives).

Congruence and case strength. Results of a linear regression analysis revealed that participants in the congruent condition perceived the Defense's case was significantly stronger than those in the incongruent condition, $B=-1.08, S E=.29, \beta=-.36, p<.001,95 \% \mathrm{CI}[-1.66$, .51]. Results of this analysis also revealed that participants in the incongruent condition perceived the Prosecution's case was significantly stronger than participants in the congruent condition, $B=.98, S E=.24, \beta=.38, p<.001,95 \% \mathrm{CI}[.50,1.46]$. There was no interaction between congruence and modality on the Defense's case strength, $B=-15, S E=.23, \beta=-.08, p=$ 
$.506,95 \%$ CI $[-.59, .29]$, or the Prosecution's case strength, $B=.012, S E=.19, \beta=.007, p=$ $.951,95 \%$ CI $[-.36, .38]$.

Evidence modality and case strength. Results of a linear regression analysis revealed that evidence modality did not have a significant effect on participants' perceptions of the Defense's case strength, $B=.23, S E=.16, \beta=.12, \mathrm{p}=.149,95 \%$ CI $[-.08, .55]$. Evidence modality did, however, have a significant effect on participations' perceptions of the Prosecution's case strength, $B=-.32, S E=.13, \beta=-.20, p<.05,95 \%$ CI [-56, -.06]. Specifically, those in the no-aid condition perceived the Prosecution's case was significantly stronger than those in the computer-generated animation condition, $B=-.29, S E=.11, \beta=-.18, p<.05,95 \%$ CI [-.50, -.07]; however, this difference was not significant between participants in the no-aid condition and those in the static visual condition, $B=-.06, S E=.11, \beta=-.04, p=.586,95 \% \mathrm{CI}[-$ $.27, .15]$

Table 4

Case Strength as a Function of Evidence Congruence and Modality

Congruence

Modality
Incongruent
Congruent
Total

\begin{tabular}{ccccccc}
\hline & $\mathrm{M}$ & $\mathrm{SD}$ & $\mathrm{M}$ & $\mathrm{SD}$ & $\mathrm{M}$ & $\mathrm{SD}$ \\
\hline Prosecution's Case & & & & & & \\
No-aid & 6.00 & .84 & 4.86 & 1.18 & $\mathbf{5 . 4 6}$ & 1.16 \\
$\begin{array}{l}\text { Static Visuals } \\
\text { Animation }\end{array}$ & 5.38 & 1.43 & 4.69 & 1.20 & $\mathbf{5 . 0 4}$ & 1.35 \\
& 5.38 & 1.16 & 4.26 & 1.17 & $\mathbf{4 . 8 0}$ & 1.29 \\
\hline Total & $\mathbf{5 . 6 0}$ & 1.19 & $\mathbf{4 . 5 8}$ & 1.21 & 5.10 & 1.30 \\
\hline
\end{tabular}

Defense's Case 


\begin{tabular}{|c|c|c|c|c|c|c|}
\hline No-aid & 3.10 & 1.78 & 4.27 & 1.50 & 3.66 & 1.74 \\
\hline Static Visuals & 3.13 & 1.46 & 4.21 & 1.06 & 3.68 & 1.37 \\
\hline Animation & 3.26 & 1.35 & 4.73 & 1.15 & 4.01 & 1.45 \\
\hline & 3.16 & 1.53 & 4.41 & 1.26 & 3.78 & 1.53 \\
\hline
\end{tabular}

Perceptions of attorney efficacy. Participants were asked to report their perceptions about the Prosecutor and the Defense Attorney's preparedness, credibility, competency and persuasiveness. Their perceptions about each of these four qualities were reported on a scale ranging from 0 (Not at all) to 7 (Extremely). The four scale items measuring the Prosecutor and Defense Attorney's overall performance demonstrated good internal consistency $(\alpha=.87$ and $\alpha$ $=.91$, respectively) which justified the creation of a composite variable. Thus, a composite variable referring to the attorney's overall efficacy was created by summing participants' mean scores on each of these four measures. Results of a paired samples t-test revealed that, on average, participants perceived the Prosecutor to have greater efficacy than the Defense Attorney, $t(219)=6.48, S D=.6 .41 p<.001,95 \%$ CI $[1.95,3.65]$ (see Table 5 for descriptives). For exploratory purposes, we investigated whether evidence congruence or modality predicted perceptions of each attorney's efficacy during trial.

Congruence and perceptions of attorney efficacy. Results of a linear regression analysis revealed that participants in the congruent condition perceived the Defense Attorney's efficacy was significantly greater than those in the incongruent condition, $B=-3.46, S E=.68, p<.001$, 95\% CI [-4.80, -2.12]. Results of this analysis also revealed that participants in the incongruent condition perceived the Prosecutor's overall efficacy was significantly greater than participants in the congruent condition, $B=1.56, S E=.60, p<.05,95 \% \mathrm{CI}[.37,2.74]$. There was no significant interaction between evidence congruence and modality on participants' perceptions of 
the Defense's attorney's efficacy, $B=-96, S E=.84, \beta=-.14, p=.252,95 \%$ CI [-2.61, .69], or the Prosecutor's efficacy, $B=-.06, S E=.74, \beta=-.009, p=.940,95 \%$ CI $[-1.51,1.40]$.

Modality and perceptions of attorney efficacy. Results of a linear regression analysis revealed that evidence modality did not have a significant effect on participants' perceptions of the Defense Attorney's efficacy, $B=.64, S E=.42, \beta=.10, p=.128,95 \%$ CI $[-.19,1.46]$, nor did evidence modality have a significant effect on perceptions of the Prosecutor's efficacy, $B=-.47$, $S E=.37, \beta=-.08, p=.207,95 \%$ CI $[-1.19, .26]$.

Table 5

Attorney Efficacy as a Function of Evidence Congruence and Modality

Congruence

Modality
Incongruent
Congruent
Total

\begin{tabular}{|c|c|c|c|c|c|c|}
\hline & $\mathrm{M}$ & SD & $\mathrm{M}$ & SD & $\mathrm{M}$ & $\mathrm{SD}$ \\
\hline \multicolumn{7}{|l|}{ Prosecutor } \\
\hline No-aid & 21.85 & 4.49 & 20.49 & 4.71 & 21.21 & 4.62 \\
\hline Static Visuals & 22.67 & 4.19 & 20.56 & 4.17 & 21.62 & 4.29 \\
\hline Animation & 20.85 & 4.77 & 19.63 & 5.26 & 20.22 & 5.03 \\
\hline Total & 21.79 & 4.51 & 20.21 & 4.72 & 21.01 & 4.67 \\
\hline \multicolumn{7}{|l|}{ Defense Attorney } \\
\hline No-aid & 15.94 & 5.16 & 18.34 & 5.19 & 17.14 & 5.28 \\
\hline Static Visuals & 16.49 & 6.28 & 20.05 & 4.30 & 18.32 & 5.61 \\
\hline Animation & 16.23 & 4.60 & 20.56 & 4.54 & 18.54 & 5.04 \\
\hline Total & 16.22 & 5.36 & 19.71 & 4.73 & 18.02 & 5.33 \\
\hline
\end{tabular}


Perceptions of defendant's testimony. Participants were asked to report their perceptions of how convincing the defendant's testimony was on a scale ranging from 0 (Not at all Convincing) to 7 (Extremely Convincing). For exploratory purposes, we investigated whether evidence congruence and/or modality predicted positive perceptions of the defendant's testimony (see Table 6 for descriptives).

Evidence congruence and perceptions of defendant's testimony. Results of a linear regression analysis revealed that participants in the congruent condition perceived the defendant's testimony was more convincing than those in the incongruent condition, $B=-1.65$, $S E=.22, \beta=-.44, \mathrm{p}<.001,95 \% \mathrm{CI}[-2.08,-1.21]$. The interaction between evidence congruence and modality on perceptions of the defendant's testimony was not significant, $B=-.15, S E=.27$, $\beta=-.06, p=.580,95 \%$ CI $[-.69, .39]$.

Evidence modality and perceptions of defendant's testimony. Results of a linear regression analysis revealed that evidence modality had a significant effect on participants' perceptions of how convincing the defendant's testimony was, $B=.36, S E=.14, \beta=.16, \mathrm{p}<.05$, $95 \%$ CI $[.09, .63]$. Specifically, those in the no-aid condition perceived the defendant's testimony was significantly less convincing than those in the computer-generated animation condition, $B=$ $.42, S E=.16, \beta=.18, p<.05,95 \% \mathrm{CI}[.11, .73]$; however, this difference was not significant between participants in the no-aid condition and those in the static visual condition, $B=-.13, S E$ $=.16, \beta=-.06, p=.398,95 \%$ CI $[-.44, .18]$. 
Table 6

Defendant's Credibility as a Function of Evidence Congruence and Modality

Congruence

Modality

Incongruent

Congruent

Total

\begin{tabular}{|c|c|c|c|c|c|c|}
\hline & $\mathrm{M}$ & SD & $\bar{M}$ & $\mathrm{SD}$ & $\mathrm{M}$ & SD \\
\hline No-aid & 2.26 & 1.43 & 3.76 & 1.87 & 3.00 & 1.82 \\
\hline Static Visuals & 2.34 & 1.76 & 4.00 & 1.47 & 3.18 & 1.81 \\
\hline Animation & 2.83 & 1.77 & 4.62 & 1.66 & 3.77 & 1.93 \\
\hline & 2.47 & 1.66 & 4.13 & 1.70 & 3.31 & 1.87 \\
\hline
\end{tabular}

\section{Mediation Analyses}

In the current study, participants who viewed a persuasive computer-generated animation depicting the defendant's version of events in the crime were more likely to report that this defendant was not-guilty of second-degree murder. The aforementioned valuations of the strength of the case evidence or perceptions about the defendant's testimony may have, at least in part, contributed to the significant main effect of evidence modality on participants' verdict decisions. Therefore, additional analyses were conducted to test the possibility that the effects of evidence modality on participants' verdicts were by mediated by participants' perceptions of the Prosecution's case strength, or participants' perceptions of the defendant's testimony. These two mediators were selected as both were significantly predicted by evidence modality in previous analyses - a criterion which is necessary in order for full or partial mediation to occur 
(Baron \& Kenny, 1986; Collins et al., 1998; Kenny et al., 1998; Shrout \& Bolger, 2002). In order to examine mediation and overall fit, a causal model was tested for each of the two main effects (i.e., perceptions of the Prosecution's case strength and perceptions of the defendant's testimony) as mediators of the relationship between evidence modality and verdict.

Using PROCESS in SPSS, we first entered evidence modality as a predictor variable, perceptions of the Prosecutor's case strength as a mediator, and verdict as an outcome variable. As presented in Figure 5, the results indicated that evidence modality was a significant predictor of perceptions of the Prosecution's case strength, $B=-.33, S E=.10, p<.001,95 \%$ CI $[-.53$, .13] and that perceptions of the Prosecution's case strength was a significant predictor of verdict, $B=-1.11, S E=.16, p<.001,95 \%$ CI $[-1.43,-.79]$. When controlling for the mediating effect of Prosecution's case strength, evidence modality still significantly predicted verdict, $B=.64, S E=$ $.22, p<.05,95 \%$ CI $[.22,1.07]$ indicating partial mediation. Approximately $4.4 \%$ of the variance in verdict was accounted for by the predictors $\left(R_{2}=.0438\right)$. The indirect effect was tested using a percentile bootstrap estimation approach with 5000 samples (Shrout \& Bolger, 2002), implemented with the PROCESS macro Version 3 (Hayes, 2017). These results indicated the indirect coefficient was significant, $B=.37, S E=.13,95 \% \mathrm{CI}[.15, .67]$. Thus, perceptions of the Prosecution's case strength partially mediated the relationship between evidence modality and verdict.

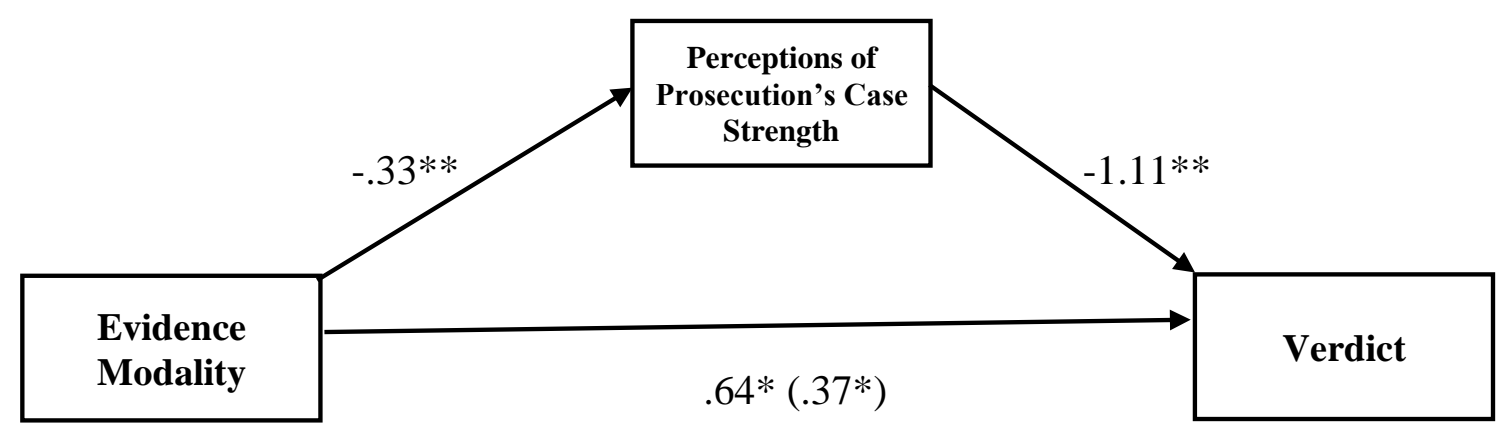


Figure 5. Unstandardized regression coefficients for the relationship between evidence modality and verdict as mediated by perceptions of the Prosecution's case strength. The unstandardized coefficient between evidence modality and verdict, controlling for perceptions of the Prosecution's case strength, is in parentheses. ${ }^{*} p<.05,{ }^{*} p<.001$.

Next, we entered evidence modality as a predictor variable, perceptions of the defendant's testimony as a mediator, and verdict as an outcome variable. As presented in Figure 6 , the results of the mediation analysis indicated that evidence modality was a significant predictor of perceptions of the defendant's testimony, $B=.38, S E=.15, p<.05,95 \% \mathrm{CI}[.09$, .68 , and that perceptions of the defendant's testimony was a significant predictor of verdict, $B=$ $1.01, S E=.14, p<.001,95 \% \mathrm{CI}[0.74,1.29]$. When controlling for the mediating effect of the defendant's testimony, evidence modality still significantly predicted verdict, $B=.84, S E=0.24$, $p<.001,95 \%$ CI $[0.37,1.31]$, consistent with partial mediation. Approximately $2.8 \%$ of the variance in verdict was accounted for by the predictors $\left(R_{2}=.028\right)$. The indirect effect was tested using a percentile bootstrap estimation approach with 5000 samples (Shrout \& Bolger, 2002), implemented with the PROCESS macro Version 3 (Hayes, 2017). These results indicated the indirect coefficient was significant, $B=.39, S E=.17,95 \%$ CI [0.06, 0.74]. Thus, perceptions of the defendant's testimony partially mediated the relationship between evidence modality and verdict.

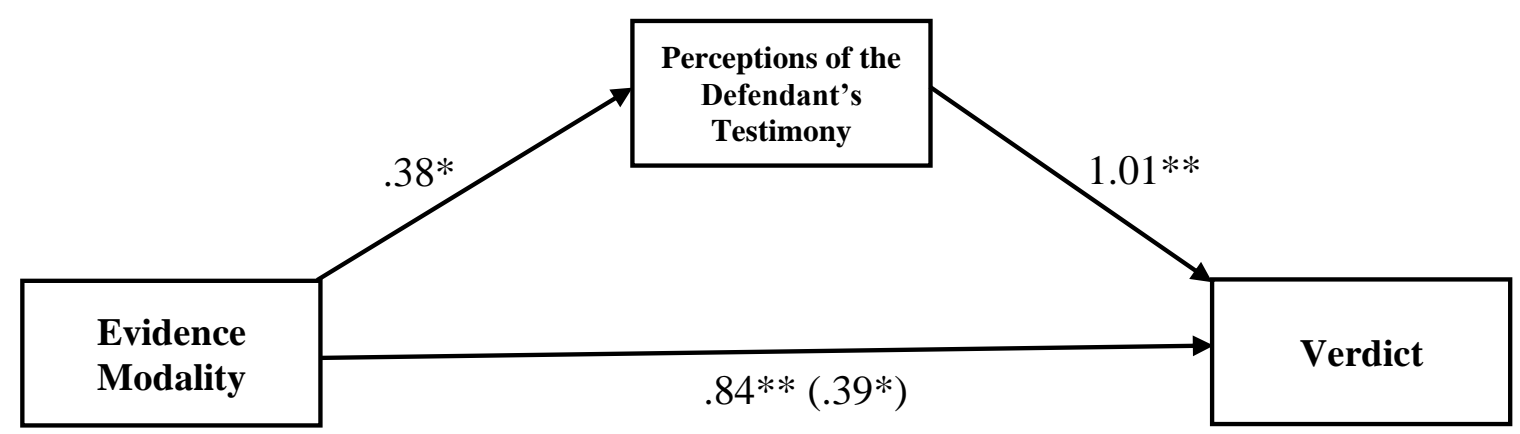


Figure 6. Unstandardized regression coefficients for the relationship between evidence modality and verdict as mediated by perceptions of the Defendant's testimony. The unstandardized coefficient between evidence modality and verdict, controlling for perceptions of the defendant's testimony, is in parentheses. $* p<.05, * * p<.001$.

\section{Discussion}

The current study investigated whether computer-generated animations affect jurors’ decisions differently from more traditional forms of evidence, such as oral testimony or static visual aids. Although previous studies have explored the persuasive effects of computergenerated animations within civils trials, the present study is the first to do so within a mock criminal trial, and thus represents a valuable contribution to the limited experimental research on computer-generated animations and other emergent digital technologies in the courtroom.

The first hypothesis - that jurors who received testimony from a defendant which was congruent with other case evidence would be more likely to render not-guilty verdicts than mock jurors who received testimony that was incongruent with other case evidence - was supported. The results demonstrated that the majority of participants favoured the Prosecution's case; participants convicted the defendant at a rate of $67.6 \%$, whereas only $32.4 \%$ rendered an acquittal. These findings align with criminal trial data from both Canada and the U.S., which indicate that the majority culminate with a conviction (Department of Justice, U.S., 2012; Statistics Canada, 2017). An examination of the distribution of verdicts by condition demonstrated that in the congruent condition, a slight majority $(53.4 \%)$ of participants chose to acquit the defendant (i.e., an 'informed' verdict). In the incongruent condition, however, participants overwhelmingly favoured the Prosecution's argument, such that $87.7 \%$ of participants convicted the defendant (i.e., an 'informed' verdict). 
These results demonstrate that participants in our study were cognizant of the degree to which the defendant's testimony aligned or conflicted with other case evidence, and that they used this information to render appropriate verdicts. It is worth noting that the equivocal distribution of verdicts in the congruent condition reflects that participants in the congruent condition were less persuaded by the dominant case argument in their respective trial transcript (i.e., Pro-Defense transcript) than were those in the incongruent condition (i.e., Pro-Prosecution transcript). Nevertheless, our results supported the hypothesized effects of evidence congruence, allowing us to explore our primary research question: how do computer-generated animations affect jurors' judgments when the account depicted in the animation aligns, and when it conflicts, with other case evidence?

Accordingly, the second hypothesis - that the use of a computer-generated animation to illustrate a defendant's testimony would have both facilitative and prejudicial effects on jurors was also supported. In the current study, participants were significantly more likely to acquit the defendant when his testimony was accompanied by a computer-generated animation $(51.25 \%$ rate of acquittal), than when it was accompanied by a static visual aid (25.0\%) or was not accompanied by a visual aid (20.5\%). Given that this effect occurred across congruence conditions, the study lends empirical support to Kassin and Dunn's (1997) facilitation and prejudice hypotheses. In other words, when case evidence from other witnesses corroborates a defendant's testimony, the use of a computer-generated animation can facilitate mock jurors' judgments, bringing them more in line with the facts of the case. When case evidence conflicts with a defendant's testimony, however, computer-generated animations can also prejudice mock jurors' judgments, such that jurors tend to over rely on the scenario depicted in the animation and fail to appropriately consider other probative evidence which would be valuable to their 
decisions about a defendant's guilt or innocence.

The observed effects of modality and verdict are in line with dual-coding hypothesis (Paivio, 2007; Sadoski \& Paivio, 2013), which posits that the use of coordinated verbal-visual components in a presentation enhances the effectiveness of learning, as well as its extended theoretical framework on cognitive multimedia learning (Mayer, 2014), which predicts that meaningful learning occurs when individuals have the opportunity to mentally construct coherent knowledge representations from material they are provided with (Mayer \& Moreno, 2002). The results observed in the current study may be attributable - at least in part - to the nature of the computer-generated animation that was used in the study. The multimedia principle (Mayer \& Moreno, 2002), for example, states that individuals learn more deeply from animation and narration than from narration alone. The modality principle (Mayer \& Moreno, 2002) suggests that individuals learn more deeply from animation and narration than from animation and onscreen text, due to an individual being able to process information via two distinct channels, thus avoiding cognitive overload from multiple visual inputs. Finally, the personalization principle (Mayer \& Moreno, 2002), explains that individuals learn more deeply from animation and narration when the narration is in conversational style (i.e., using first- and second-person constructions such as "I" or "you") rather than formal style. Given the extent to which our digital materials (i.e., a highly realistic computer-generated animation with simultaneous first-person, oral narration) corresponded with these criteria for learning, it reasonably follows that the animation that was employed in this study would have a robust impact on mock jurors' verdicts. In addition to our primary dependent variable (i.e., verdict), our study also investigated a number of exploratory dependent variables. Although we did not prepare a priori hypotheses about the effects of evidence modality and congruence on these variables, our analyses 
demonstrated significant effects that were valuable to the interpretation of our main findings. First and foremost, we had participants report how confident they felt in their verdicts, as well as how probable it was that the defendant in question did, in fact, commit second-degree murder. Of note, probability of guilt estimates and confidence in verdict were positively correlated, such that participants who felt more strongly about the defendant's culpability also displayed greater confidence in their verdicts.

According to Kassin and Wrightsman (1983), judgments of guilt arise when jurors' estimates of an individual's probability of guilt exceed their criterion for reasonable doubt. Unsurprisingly, we observed a negative relationship between participants' probability of guilt estimates and not-guilty verdicts. In other words, participants who were strongly convinced of the defendant's guilt were less likely to render a not-guilty verdict. In line with the case evidence, participants in the incongruent condition reported higher probability of guilt estimates than those in the congruent condition. Accordingly, these individuals - who held strong beliefs about the defendant's culpability - also felt more confident in their verdicts than did those in the congruent condition, who were less certain. In terms of modality, participants who viewed the computer-generated animation were less convinced of the defendant's guilt than those in the noaid or static visual aid condition and were also less confident in their verdicts.

Our findings also suggest that participants in the incongruent condition - who were presented with conflicting information from witnesses - were adept at detecting inconsistencies in the defendant's testimony, which may have bolstered their opinions of the defendant's guilt and their confidence in a guilty verdict. In the congruent condition, where the vast majority of evidence supported the defendant's version of events, participants did acquit the defendant (at a rate of 54.4\%) but appeared to do so hesitantly, and with private reservations about this decision. 
With regard to evidence modality, the results fit well with our supposition regarding the persuasive capacity of animations. Individuals were compelled by the narrative depicted within the computer-generated animation to such a degree that it diminished their opinions of the defendant's guilt, and aroused a sense of doubt in their verdicts. These secondary measures (i.e., probability of guilt estimates and confidence in verdict) provide valuable supplementary information about why jurors chose a particular verdict, and how they privately felt about these verdicts.

While not a primary focus of our study, we investigated whether various covariate measures predicted participants' verdicts. Two of our covariate scales (e.g., Juror Bias Scale and ATST) demonstrated poor internal consistency; thus the results derived from these scales should be interpreted with caution. The Perceptions of Police scale, however, demonstrated good internal consistency. A logistic regression analysis revealed that our results did not vary as a function or participants' age, gender identity or ethnicity, nor did they vary due to participants' pro-prosecution/pro-defense biases or attitudes toward technology. Participants' perceptions of police, however, did have a significant effect on participants' verdicts such that individuals who held more favourable attitudes toward police officers were more likely to report that the defendant in the case - Officer Gary Green - was not-guilty of second-degree murder.

This finding also brings to light the socially-charged nature of the mock trial materials that were used in the current study. In recent years, a great deal of media attention has been paid to violence against African American males at the hands of white police officers. Such events have incited social initiatives including "Black Lives Matter," that have gained much attention and have reasonably deteriorated public confidence in police officers. Given the particular trial materials used in the current study (i.e., a mock trial featuring a white male police officer, and an 
African American victim), participants may have been influenced by coverage of similar events in the media, and their attitudes toward police officers may have been more negative than had these events not been particularly salient at the time of this study. Despite this significant covariate, however, both modality and congruence remained significant, suggesting that the results of both variables on participants' verdicts are robust.

The results of this study fit well with psychological theory regarding jurors' decisionmaking processes (e.g., the Story Model), as well as existing cognitive research on persuasion (e.g., the Elaboration Likelihood Model) and learning (e.g., Multimedia Learning Theory). The disproportionate effect of a computer-generated animation on jurors' judgments suggests that individuals process this modality differently than they do other visual and oral forms of testimonial evidence.

In effect, the Story Model predicts that imagination from the starting point of a visual animation would require less effort and attention than imagination from a blank slate (Pennington \& Hastie, 1992). It may be the case that mock jurors in our study had to expend substantially less effort to construct a cohesive and plausible narrative about how the crime occurred when this narrative was constructed for them in the form of a computer-generated animation. Given that mock jurors in our study would likely have had limited personal experience or knowledge about the pertinent events in the case, the narrative depicted in the animation appears to have become a key reference for jurors - one which they heavily relied on and integrated into their judgments. This finding aligns with research by Dunn, Salovey and Feigenson (2006) that previously demonstrated that an individual's level of familiarity with case material can, in fact, mediate the impact of computer-generated animations on jurors' judgments. 
Consistent with research by Selbak (1994) our results suggest that mock jurors seemingly possessed a limited awareness of the effects of this animation on their judgments. Participants' open-ended responses did not vary across modality conditions, revealing that participants who viewed a computer-generated animation - despite being considerably influenced by the visual depiction - did not overtly report that the impact of this visual aid on their ultimate judgments. This result could potentially indicate that the animation was not perceptibly more salient to mock jurors than other forms of testimony, suggesting that mock jurors may have processed this video in a peripheral way. Another possibility, however, is that jurors hesitated to report the animation as a factor impacting their judgments because they were not explicitly asked about its effects on their judgments. Previous studies (e.g., Bennett, Liebman \& Fetter; 1999; Dunn, Salovey \& Feigenson, 2006) have asked participants to quantitatively rate the influence of animations to their ultimate judgments, whereas the current study used an open-report format, without an overt prompt to guiding their attention to the effects of the animation, specifically. It could be the case that jurors were, in fact, cognizant of the effects of animations on their judgments, but either: a) were distracted by other evidence which was presented in a closer proximity to the open-ended question, or b) did not perceive that their weight was substantially greater than other discrete pieces of evidence presented to them in the study. Future studies should consider complementing open-ended measurements with quantitative data (such as having participants rate the influence of evidence on a Likert scale) to better understand the degree to which participants' were aware of the effects of animations to their verdict judgments.

Notably, our results implicate two specific and measurable components of a trial as being part of the causal pathway between computer-generated animations and their persuasive effects on jurors. Specifically, the use of a computer-generated animation appears to have increased the 
credibility of the defendant's testimony, which - rather than bolstering the Defense's case undermined the integrity of the Prosecution's case and the narrative promoted by the Prosecution. Both exploratory variables (i.e., perceptions of the defendant's testimony and the Prosecution's case strength) were found to partially mediate the relationship between evidence modality and verdict. These findings are in line with research by Cheng and Lo (2012) and Cooper, Bennett and Sukel (1996) which demonstrated that individuals tend to draw inferences about the credibility of especially dynamic or vivid information that extend beyond the actual content of this information.

The results of this study also align with research on the effects of visual multimedia on individuals' information processing (e.g., dual-coding theory). Although the effects of animations have seldom been investigated in legal settings, research in educational and media domains suggest that animations can have facilitative effects on individuals' learning and memory. Regardless of the veracity of the events depicted in the animation, participants in our study who viewed the computer-generated animation evidently gained incidental knowledge and details from this rendering that they did not from the static visual aids. This finding is in line with research by Berry and Brosius (1991) who found that crime news with video crime footage was superior to "talking heads" narrated news reports in terms of information acquisition, and supports that the dynamic nature of animations may make them superior to existing visual aids in terms of disseminating information to viewers. Although the precise mechanisms underlying this effect remain unknown, animations appear to facilitate jurors' cognitive processing of information, such that they promote learning above and beyond existing presentation aids.

\section{Implications}


Aside from its theoretical value, the present study produced findings that have applied utility within the criminal justice system. First and foremost, the current study provides novel information about the probative and prejudicial value of computer-generated animations. Our findings support the conclusion that animations can both enhance and hinder participants' legal decision-making, depending on the context of their presentation. Given that Federal Rule of Evidence 403 dictates that evidence must be excluded from trial if its probative value is substantially outweighed by the danger of unfair prejudice, the admittance of potentially misleading or inflammatory animations may violate trial principles and serve as a form of evidentiary misconduct. Undoubtedly, these findings may serve as a reference for judges in their appraisal of this evidence, and as an educational tool for legal professionals who seek to develop this novel form of evidence in accordance with federal regulations. Although our findings undoubtedly provide a valuable starting point for this assessment, future research is needed to determine what constitutes an acceptable level of prejudice within in an animation, and where the tipping point is for prejudice outweighing probative value.

As with other demonstrative aids, the purpose of computer-generated animations is to illustrate testimony in a way that is an accurate representation of the facts of the case, and fair and absent of any intention to mislead. Although animations have demonstrated a facilitative effect on jurors' judgments under certain circumstances, they have also demonstrated a capacity to misrepresent case facts and mislead jurors. It could be the case that jurors are misconstruing the version of events depicted in the animation as being factual, rather than as a theory of events derived from interviews with involved parties or witnesses to a crime. Consequently, policymakers should certainly consider holding computer-generated animations to a higher standard of evidentiary regulation - one that is more akin to the criteria which governs 
substantive evidence. As is the case with original evidence, lawmakers may wish to consider requiring attorneys to establish the relevancy, materiality and authenticity of an animation prior to it being admitted into the courtroom.

Finally, because no two crimes are identical, no two animations will be identical. Therefore, it would be difficult - if not impossible - to identify 'universal' element(s) of an animation that can be deemed as prejudicial across all circumstances. The intent of this study and this line of research in general - is not to isolate specific graphical elements (e.g., angles, colours or details) of an animation and mandate their inclusion or exclusion into court, but rather to provide empirical evidence that the dynamic visual and auditory qualities of animations may have a synergistic effect on jurors, and to encourage judges to be mindful of this when determining their admissibility.

\section{Limitations and Future Directions}

There are limitations to the current study that should be considered when interpreting the results. Despite our sample of participants representing a relatively diverse range of ethnic backgrounds, our sample consisted exclusively of undergraduate students - a population which is known to be homogenous, and to vary systematically from the general population, in a number of ways. In addition, although we made every attempt to replicate the experience of real jurors and the circumstances of a real trial, this study was conducted in a controlled, laboratory setting with simplified trial materials. It is important to note that the mock jurors in our study were instructed to work individually for the duration of the study and did not have the opportunity to deliberate with a jury of their peers before rendering their verdicts. Thus, it is difficult to conclude whether the results of this controlled experiment - wherein certain components of a real trial were noticeably absent - would generalize to real trial settings, which are substantially 
more complex in nature and transpire over a much longer duration than the present study. In order to further validate our results, future research should aim to test the external validity of our findings by sampling actual courtroom jurors in real criminal trials.

Although these findings represent a valuable addition to the extant research on computergenerated animations in legal settings, further research is needed to provide a holistic portrayal of the effects of these animations on jurors' cognition and judgments. In the current study, we explored how a computer-generated rendering of a defendant's testimony affected jurors' verdicts in a criminal trial. With this said, the study was limited in that the animation was presented by only one legal party (i.e., the Defense) rather than by both attorneys. Research exploring other digital presentation technologies (i.e., PowerPoint $\AA^{\circledR}$ ) has shown jurors are most persuaded by digital technologies when their use is differential. In a real trial setting, the Prosecution would have the opportunity to produce a comparable animation depicting an opposing version of events, which could reasonably mitigate the degree to which jurors attend to and rely on the events depicted in the Defense's animation. It would be advantageous to explore whether and/or how jurors' judgments are affected when animations are used by both legal parties, rather than by only one party and - in addition - to determine whether the order of presentation impacts the saliency of an animation in jurors' cognition and subsequent judgments. In addition, it is worth exploring the extent to which the quality of a given animation contributes to its utility in the courtroom. Preliminary research by Bennett, Liebman and Fetter (1999) indicates that individuals' perceptions about an animation's quality do not moderate its ultimate effect on their judgments. In the current study, the observed facilitative and prejudicial effects closely mirror those of Kassin and Dunn (1997), despite the current animation being substantially more realistic and technologically-advanced than the original. Accordingly, it 
would appear that it is the mere presence of an animation - rather than the quality or realism of the animation - that may be especially important to jurors' cognitive processing of its content. In scenarios where jurors are exposed to a dynamic, visual animation which enhances their ability to construct a cohesive narrative of the crime, the effects of an animation on their judgments should remain consistent, regardless of the animation's quality. Future investigations should certainly consider exploring how qualitative changes to an animation (e.g., low vs. high quality, 2-D vs. 3-D, colour vs. black and white) contributes to its effect on jurors and its persuasiveness in the courtroom.

Given the disproportionate probative weight that mock jurors' assign to computergenerated animations - coupled with the fact that jurors appear to be relatively unaware of their influence on their judgments - it would be beneficial to investigate potential remedial procedures that could attenuate the observed effects. Some research has shown that cautionary or 'limiting' instructions delivered by a judge before or after evidence presentation may be effective in mitigating jurors' reliance on potentially prejudicial evidence (see Ogloff \& Rose, 2005 for a review). Although limiting instructions have traditionally been implemented to caution jurors about the reliability of eyewitness testimony (e.g., Cutler, Dexter \& Penrod, 1990) or excessively gruesome evidence (e.g., Cush \& Delahunty, 2006) some scholars have proposed that they be employed proximally to the presentation of computer-generated animations to reduce their prejudicial impact (Hadley, 2009). Future research should investigate whether the presentation of limiting instructions - which encourage due diligence when evaluating computer-generated animations - are effective at reducing jurors' reliance on animations. These instructions may serve as a reminder to jurors that animations do not necessarily depict a factual version of events, and emphasize to jurors that they should be evaluated with caution. 
Finally, the current study used participants' verdicts as an outcome measure to assess the persuasive effects of computer-generated animations. Although the study was successful in capturing a product of subjects' appraisal of the animation, the study did not incorporate any process measures that would allow us to determine how these animations are impacting jurors' verdicts. Future research should aim to determine the specific cognitive (e.g., comprehension, memory, or attention) and/or affective (e.g., physiological or emotional arousal) mechanisms that are driving the persuasive effects of computer-generated animations on jurors' verdicts.

\section{Conclusion}

Computer-generated animations are being admitted into court with increasing regularity yet, to date, there has been limited empirical research which has evaluated their effects on jurors. Consequently, little is known about the persuasive capacity of computer-generated animations, and whether they enhance or hinder juror's decision-making during trial. We aimed to investigate the facilitative and prejudicial effects of computer-generated animations on jurors' judgments. Extending on preliminary research by Kassin and Dunn (1997), we found support for the facilitation and prejudice hypotheses in a novel criminal case with updated trial materials, and an animation that was substantially more advanced than the original.

In addition, our study investigated a number of exploratory variables which further elucidated how computer-generated animations exert an impact on jurors' cognition. In addition to affecting mock jurors' verdicts, the use of a computer-generated animation diminished individuals' estimates of the defendant's guilt, as well as their confidence in their verdicts. Our results also showed that the use of a computer-generated animation increased the credibility of the defendant's testimony, which served to undermine the integrity of the Prosecution's case. Despite the observed influence of the computer-generated animations, participants in our study 
demonstrated a limited awareness of the effects of this animation on their judgments. This finding suggests either that jurors may have misinterpreted the content in the animation as factual (rather than as only a version of events), or that the animation was processed in a peripheral way, that evaded participants' conscious awareness.

Given the paucity of research directly investigating how computer-generated animations affect jurors' decision-making, the applied implications of this research are numerous. The results of this study strongly suggest that computer-generated animations should not be considered as akin to other forms of demonstrative evidence (i.e., photographs, visual renderings, maps, etc.) due to their substantial persuasive capacity. Given that evidentiary misconduct has been identified as a known contributor to wrongful convictions, it is crucial that this form of evidence is properly validated by the appropriate evidentiary regulations before being admitted into trial. Accordingly, our findings regarding the probative and prejudicial value of computergenerated animations have applied utility in the criminal justice system, and may assist judges in the appraisal and regulation of this novel form of digital evidence. Future studies should aim to test our findings in ecologically valid settings (such as in a real courtroom, and with real jurors), and determine the cognitive and affective mechanisms which are driving the observed effects. 


\section{Appendix A}

\section{List of Witnesses}

\begin{tabular}{|l|l|c|c|}
\hline Name & Role & Pro- Prosecution & Pro-Defense \\
\hline 1) Jamal Williams & Victim's Friend & $\checkmark$ & \\
\hline 2) Ray Young & Eyewitness & $\checkmark$ & $\checkmark$ \\
\hline 3) Patrick Simms & Chief of Police Training & $\checkmark$ & \\
\hline 4) Laura Lee & Paramedic on Scene & & \\
\hline 5) Dr. David & Forensic Pathologist & $\checkmark$ & $\checkmark$ \\
\hline 6) Gary Green* & Defendant & & \\
\hline 7) Simon Callaghan & Defendant's Patrol Partner & & \\
\hline 8) Lucinda & School Counsellor & & \\
\hline Armstrong & & & \\
\hline
\end{tabular}




\section{Appendix B}

\section{Different voice)}

Q: Mr. Green, could you please walk us through the series of events that occurred on the evening of June 24 th?

We11, as Officer Callaghan mentioned, we were just finishing our patrol shift when we got the call about the pawn shop robbery.

-video starts -

\section{$0: 00-0: 14 s$}

As Officer Callaghan and I drove up Poinsettia Ave, we noticed a group of 4 black males walking toward us. They looked to be in their mid 20s, and appeared to match the description of the suspects in the pawn shop robbery.

$0: 15 s-0: 27$.

Their demeanor seemed off to me - they were hesitant to cross the street when they saw our police cruiser, and they weren' $t$ making eye contact. *Pause* That's when I decided we should get out of the vehicle and talk to them.

$0: 34-0: 42$

First thing I did was get out of the car, and asked them where they were headed. Then I yelled out that I wanted to see their IDs. I was firm with them, but I wasn't aggressive.

$0: 45-1: 00$

A11 of a sudden, one of the men took off running. I yelled for Officer Callaghan to stay where he was while I approached the suspect. Innocent people don't usually take off running like that for no reason. As I got closer to the suspect, I saw that he was armed.

$1: 05-1: 12$

He was a fair bit quicker than me, so by the time I got to the sidewalk, he was already almost across the road - maybe $20 \ldots 25$ feet away.

\section{$1: 14-1: 24$}

I was standing right beside the newspaper stand with my gun drawn.

At that point, I saw that he had twisted his body to aim the gun at me, and I knew that my life, and the lives of others were in danger. 


\section{$1: 26-1: 35$}

Officer Callaghan and the suspect's 3 friends were watching the situation unfold from the intersection of Rosencrantz and Poinsettia Ave.

$1: 37-1: 45$

I yelled for the suspect to put down his weapon, and when he failed to do that, I shot him in his ribcage. "Pause* He immediately fell to the ground.

$1: 48-2: 03$

I wasn't sure if he was sti11 alive. Officer Callaghan left his post and approached the suspect. I kept my weapon aimed at him incase he tried again to shoot, and Officer Callaghan checked his vitals. He told me he was unconscious, but still breathing.

$2: 04-2: 17$

I called for backup right away, and Officer Callaghan went back to contain the other 3 suspects while we waited for the paramedics to arrive. One of the suspects had already fled on foot, and it was important we contained the rest of the witnesses.

I was in complete shock. It took me a moment before I even began performing CPR, but I didn't stop until the paramedics got there and took over. Not long after, I saw them put him in a body bag, and at that point I knew he didn't make it.

I was a mess. I've never in my 15 years on the force had to use my weapon to kill another human. It's a terrible feeling, and I'm going to have to live with it my whole 1ife. Regardless of my safety being in danger, no part of me is happy that I had to resort to lethal force - especially on a 16-year-old boy. 


\section{Static Visuals}
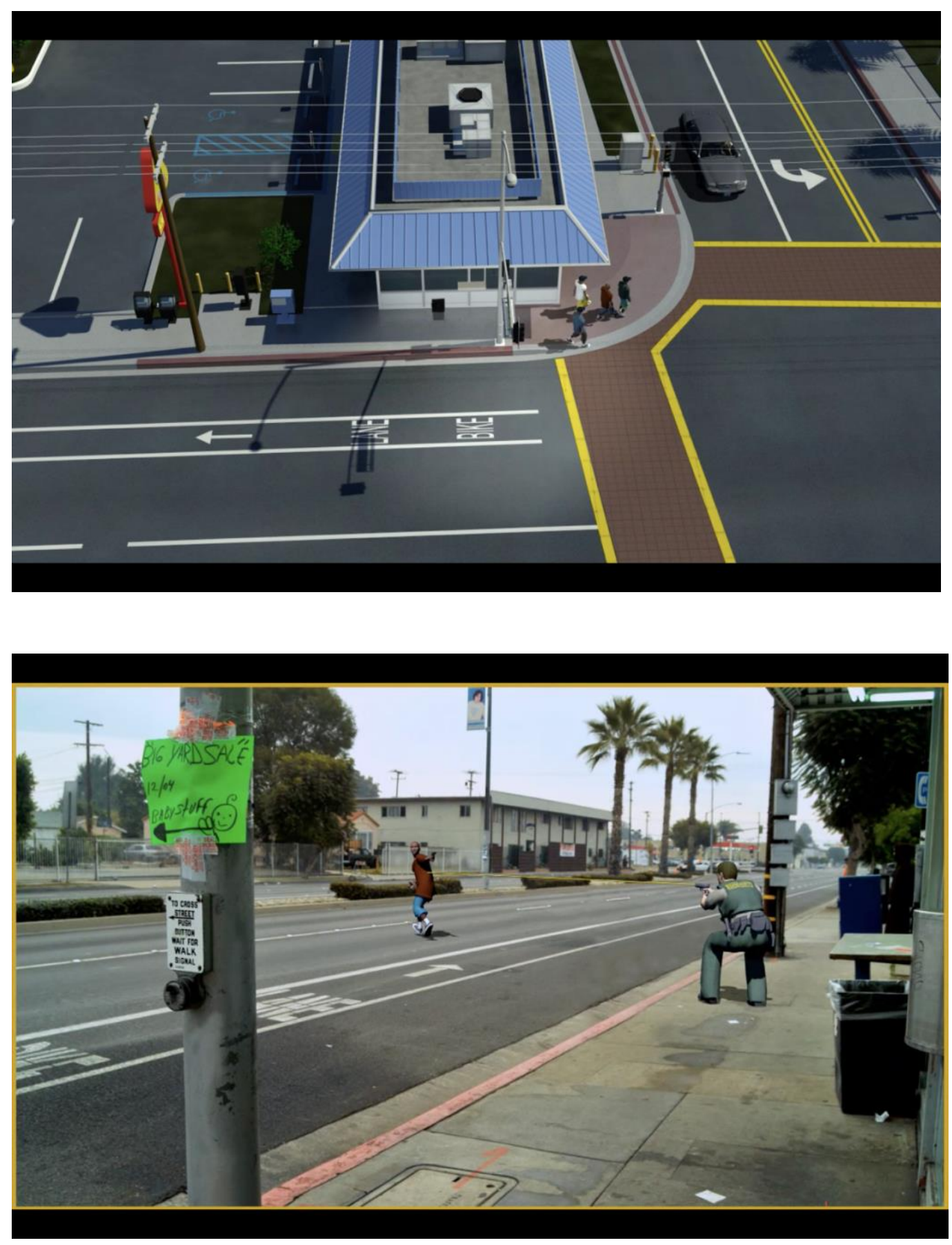

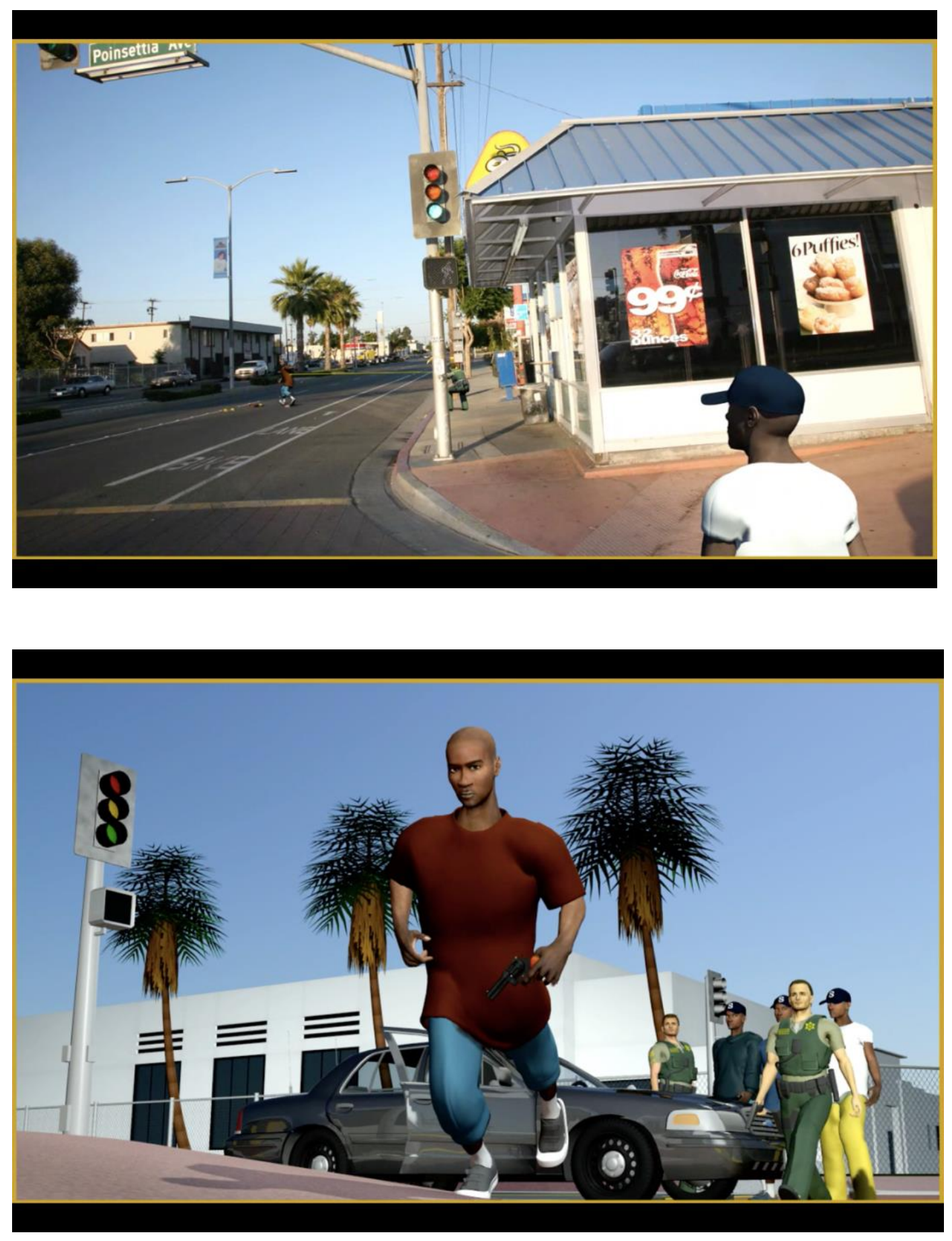


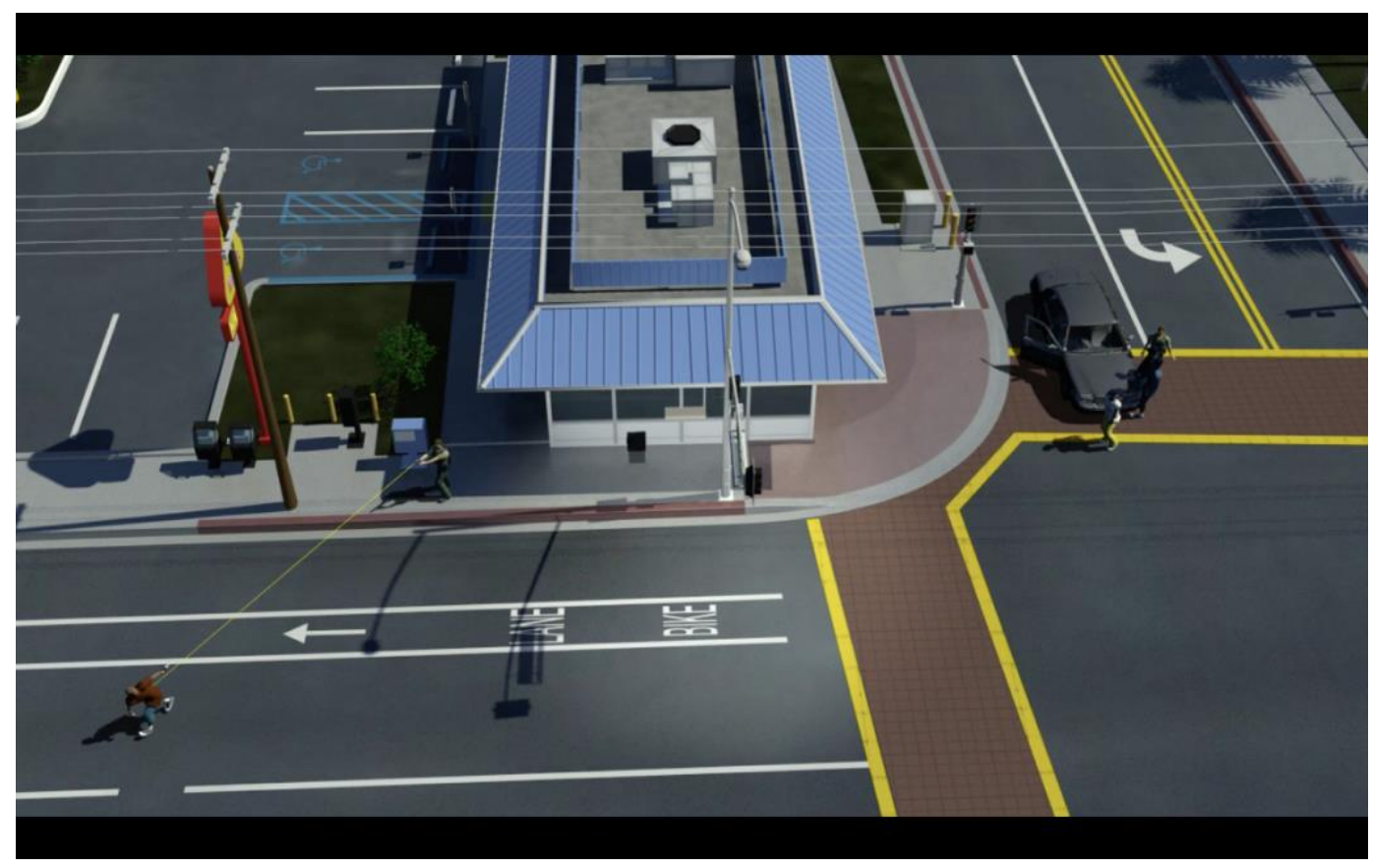




\section{Appendix D}

\section{Evidence Strength Individual Items}

Adapted from:

Koehler, J. J., Schweitzer, N. J., Saks, M. J., \& McQuiston, D. E. (2016). Science, technology, or the expert witness: What influences jurors' judgments about forensic science testimony?. Psychology, Public Policy, and Law, 22(4), 401.

Perceptions of Evidence

1. How strong was the Defense's case?

$\begin{array}{lllllll}1 & 2 & 3 & 4 & 5 & 6 & 7\end{array}$

(1 not at all strong; 7 extremely strong)

2. How strong was the Prosecution's case?

$\begin{array}{llllllll}1 & 2 & 3 & 4 & 5 & 6 & 7\end{array}$

(1 not at all convincing; 7 extremely convincing)

3. How convincing was the testimony from the defendant, Gary Green?

$\begin{array}{lllllll}1 & 2 & 3 & 4 & 5 & 6 & 7\end{array}$

(1 not at all convincing; 7 extremely convincing)

Perceptions of Attorneys (1 not at all; 7 extremely)

In your opinion, how prepared was the Defense Attorney (Mr. Michael C. Harper)?

$\begin{array}{llllllll}1 & 2 & 3 & 4 & 5 & 6 & 7\end{array}$

In your opinion, how prepared was the Prosecutor (Mr. Daniel R. Manning)?

$\begin{array}{lllllll}1 & 2 & 3 & 4 & 5 & 6 & 7\end{array}$

In your opinion, how credible was the Defense Attorney? 


$\begin{array}{lllllll}1 & 2 & 3 & 4 & 5 & 6 & 7\end{array}$

In your opinion, how credible was the Prosecutor?

$\begin{array}{llllllll}1 & 2 & 3 & 4 & 5 & 6 & 7\end{array}$

In your opinion, how competent was the Defense Attorney?

$\begin{array}{llllllll}1 & 2 & 3 & 4 & 5 & 6 & 7\end{array}$

In your opinion, how competent was the Prosecutor?

$\begin{array}{llllllll}1 & 2 & 3 & 4 & 5 & 6 & 7\end{array}$

In your opinion, how persuasive was the Defense Attorney?

$\begin{array}{llllllll}1 & 2 & 3 & 4 & 5 & 6 & 7\end{array}$

In your opinion, how competent was the Prosecutor?

$\begin{array}{llllllll}1 & 2 & 3 & 4 & 5 & 6 & 7\end{array}$

Attention Check Questions:

What was the defendant (Gary Green) charged with?
a) Aggravated assault
b) First degree murder
c) Manslaughter
d) Second degree murder

Which of the following individuals did NOT testify in the court case?
a) A forensic pathologist
b) A school counsellor
c) A bus driver
d) A paramedic

What movie was the defendant (Cody Lewis) and his friends on their way to see?
a) Harry Potter
b) A Series of Unfortunate Events
c) Hunger Games 

d) Star Wars

What State did the crime take place in?
a) Nevada
b) Michigan
c) California
d) Alabama 


\section{Appendix E}

Perceptions of Police Scale

$1=$ Strongly Disagree $2=$ Disagree $3=$ Neutral $4=$ Agree 5 $=$ Strongly Agree

Police officers are friendly

$\begin{array}{lllll}1 & 2 & 3 & 4 & 5\end{array}$

Police officers protect me

$\begin{array}{lllll}1 & 2 & 3 & 4 & 5\end{array}$

Police officers treat all people fairly

$\begin{array}{llllll}1 & 2 & 3 & 4 & 5\end{array}$

I like the police

$\begin{array}{llllll}1 & 2 & 3 & 4 & 5\end{array}$

The police are good people

$\begin{array}{llllll}1 & 2 & 3 & 4 & 5\end{array}$

The police do not discriminate

$\begin{array}{llllll}1 & 2 & 3 & 4 & 5\end{array}$

The police provide safety

$\begin{array}{llllll}1 & 2 & 3 & 4 & 5\end{array}$

The police are helpful

$\begin{array}{llllll}1 & 2 & 3 & 4 & 5\end{array}$

The police are trustworthy

$\begin{array}{llllll}1 & 2 & 3 & 4 & 5\end{array}$

The police are reliable

$\begin{array}{llllll}1 & 2 & 3 & 4 & 5\end{array}$

Police officers are unbiased

$\begin{array}{llllll}1 & 2 & 3 & 4 & 5\end{array}$

Police officers care about my community

$\begin{array}{lllll}1 & 2 & 3 & 4 & 5\end{array}$

Have you had any direct interactions with the police in the last 5 years? $\quad$ Yes No 
If so, how would you describe this interaction?

$\begin{array}{lllll}1 & 2 & 3 & 4 & 5\end{array}$

$1=$ Extremely negative $2=$ Negative $3=$ Neutral $4=$ Positive $5=$ Extremely Positive 


\section{Appendix F}

\section{Attitudes Toward Technology Scale}

$$
1=\text { Strongly Disagree } 2=\text { Disagree } 3=\text { Neutral } 4=\text { Agree 5= Strongly Agree }
$$

\section{Promise of Technology}

Technology is making our lives healthier, easier and more comfortable.

$\begin{array}{llllll}1 & 2 & 3 & 4 & 5\end{array}$

Most engineers want to work on things that will make lives better for the average person.

$\begin{array}{lllll}1 & 2 & 3 & 4 & 5\end{array}$

With the application of technology, work will become more interesting.

$\begin{array}{lllll}1 & 2 & 3 & 4 & 5\end{array}$

Because of technology, there will be more opportunities for the next generation.

$\begin{array}{lllll}1 & 2 & 3 & 4 & 5\end{array}$

Reservations about Technology

We depend too much on technology.

$\begin{array}{lllll}1 & 2 & 3 & 4 & 5\end{array}$

It is not important to utilize technology in my daily life.

$\begin{array}{lllll}1 & 2 & 3 & 4 & 5\end{array}$

Technology makes our way of life change too fast.

$\begin{array}{llllll}1 & 2 & 3 & 4 & 5\end{array}$




\section{Appendix G}

\section{Juror Bias Scale}

This is a questionnaire to determine people's attitudes and beliefs on a variety of general legal issues. Please answer each statement by giving as true a picture of your own position as possible. Please complete the survey by clicking on the number of the answer you select.

$1=$ strongly agree, $2=$ somewhat agree, $3=$ neutral, $4=$ somewhat disagree,

$$
5=\text { strongly disagree }
$$

\begin{tabular}{|c|c|c|c|c|c|c|}
\hline & $\begin{array}{l}\text { Appointed judges are more } \\
\text { competent than elected judges. }\end{array}$ & 1 & 2 & 3 & 4 & 5 \\
\hline 2) & $\begin{array}{l}\text { A suspect who runs from the police } \\
\text { most probably committed the crime. }\end{array}$ & 1 & 2 & 3 & 4 & 5 \\
\hline 3) & $\begin{array}{l}\text { A defendant should be found guilty } \\
\text { if only } 11 \text { out of } 12 \text { jurors vote. }\end{array}$ & 1 & 2 & 3 & 4 & 5 \\
\hline 4) & $\begin{array}{l}\text { Most politicians are really as honest } \\
\text { as humanly possible. }\end{array}$ & 1 & 2 & 3 & 4 & 5 \\
\hline 5) & $\begin{array}{l}\text { Too often jurors hesitate to convict } \\
\text { someone who is guilty out of pure } \\
\text { sympathy. }\end{array}$ & 1 & 2 & 3 & 4 & 5 \\
\hline 6) & $\begin{array}{l}\text { In most cases where the accused } \\
\text { presents a strong defense, it is only } \\
\text { because of a good lawyer. }\end{array}$ & 1 & 2 & 3 & 4 & 5 \\
\hline 7) & $\begin{array}{l}\text { In general, children should be } \\
\text { excused for their misbehavior. }\end{array}$ & 1 & 2 & 3 & 4 & 5 \\
\hline 8) & $\begin{array}{l}\text { The death penalty is cruel and } \\
\text { inhumane. }\end{array}$ & 1 & 2 & 3 & 4 & 5 \\
\hline 9) & $\begin{array}{l}\text { Out of every } 100 \text { people brought to } \\
\text { trial, at least } 75 \text { are guilty of the } \\
\text { crime with which they are charged. }\end{array}$ & 1 & 2 & 3 & 4 & 5 \\
\hline & $\begin{array}{l}\text { For serious crimes like murder, a } \\
\text { defendant should be found guilty if } \\
\text { there is a } 90 \% \text { chance that he } \\
\text { committed the crime. }\end{array}$ & 1 & 2 & 3 & 4 & 5 \\
\hline & $\begin{array}{l}\text { Defense lawyers don't really care } \\
\text { about guilt or innocence, they are } \\
\text { just in business to make money. }\end{array}$ & 1 & 2 & 3 & 4 & 5 \\
\hline
\end{tabular}




\begin{tabular}{|c|c|c|c|c|c|}
\hline $\begin{array}{l}\text { 12) Generally, the police make an arrest } \\
\text { only when they are sure about who } \\
\text { committed the crime. }\end{array}$ & 1 & 2 & 3 & 4 & 5 \\
\hline $\begin{array}{l}\text { 13) Circumstantial evidence is too weak } \\
\text { to use in court. }\end{array}$ & 1 & 2 & 3 & 4 & 5 \\
\hline $\begin{array}{l}\text { 14) Many accident claims filed against } \\
\text { insurance companies are phony. }\end{array}$ & 1 & 2 & 3 & 4 & 5 \\
\hline $\begin{array}{l}\text { 15) The defendant is often a victim of } \\
\text { his/her own bad reputation. }\end{array}$ & 1 & 2 & 3 & 4 & 5 \\
\hline $\begin{array}{l}\text { 16) If the grand jury recommends that } \\
\text { a person be brought to trial, then he } \\
\text { probably committed the crime. }\end{array}$ & 1 & 2 & 3 & 4 & 5 \\
\hline $\begin{array}{l}\text { 17) Extenuating circumstances should } \\
\text { not be considered - if a person } \\
\text { commits a crime, then that person } \\
\text { should be punished. }\end{array}$ & 1 & 2 & 3 & 4 & 5 \\
\hline $\begin{array}{l}\text { 18) Hypocrisy is on the increase in } \\
\text { society. }\end{array}$ & 1 & 2 & 3 & 4 & 5 \\
\hline $\begin{array}{l}\text { 19) Too many innocent people are } \\
\text { wrongfully imprisoned. }\end{array}$ & 1 & 2 & 3 & 4 & 5 \\
\hline $\begin{array}{l}\text { 20) If a majority of the evidence - but } \\
\text { not all of it - suggests that the } \\
\text { defendant committed the crime, the } \\
\text { jury should vote not-guilty. }\end{array}$ & 1 & 2 & 3 & 4 & 5 \\
\hline $\begin{array}{l}\text { 21) If the defendant committed a } \\
\text { victimless crime, like gambling or } \\
\text { possession of marijuana, he should } \\
\text { never be convicted. }\end{array}$ & 1 & 2 & 3 & 4 & 5 \\
\hline 22) Some laws are made to be broken. & 1 & 2 & 3 & 4 & 5 \\
\hline
\end{tabular}




\section{Appendix H}

\section{Demographics}

What is your age?

How would you self-identify?

$\square$ Male

$\square$ Female

$\square$ Trans

$\square$ Other, please specify

$\square$ Prefer not to answer

To which of the following ethnic and/or cultural groups do you belong?

$\square$ 1. Aboriginal

$\square$ 2. Arab

$\square$ 3. Black

$\square$ 4. Chinese

$\square$ 5. Filipino

$\square$ 6. Japanese

$\square$ 7. Korean

$\square$ 8. Latin American

$\square$ 9. South Asian (e.g., East Indian, Pakistani, Sri Lankan, etc.)

$\square$ 10. Southeast Asian (e.g., Vietnamese, Cambodian, Malaysian, Laotian, etc.)

$\square$ 11. West Asian (e.g., Iranian, Afghan, etc.)

$\square$ 12. White

$\square$ 13. Other

$\square$ 14. Prefer not to answer 


\section{Appendix I}

\section{Consent Form}

\section{Ryerson}

University

\section{Ryerson University \\ Consent Agreement}

WE THE JURY: EXAMINING THE RELATIONSHIP BETWEEN PERSONALITY AND DECISION-MAKING IN A COURT CASE

You are being asked to participate in a research study. Before you give your consent, it is important that you read the following information and ask as many questions as necessary to be sure you understand what you will be asked to do.

Primary Investigator: Emma Rempel

M.A. Student

Department of Psychology

\section{Co-Investigators: $\quad$ Dr. Tara Burke \\ Associated Professor \\ Department of Psychology}

Purpose of the Study: The purpose of this 60 minute, 1 credit social psychological study is to examine the relationship between personality and decision-making in the context of a court case. Approximately 210 Ryerson Students enrolled in PSY102 and PSY202 will participate in this study.

Description of the Study: If you decide to participate in this research, you will be asked to read a trial transcript from a criminal case with various types of evidence. You will then receive additional evidence from an eyewitness at the crime scene. Last, you will be asked to answer some brief questionnaires assessing various aspects of your personality. You will be given 1 course credit for participating.

What is Experimental in this Study: From a technical or procedural point of view, part of this study is considered "experimental," because by following the procedure described above, the study examines the impact of one variable (called the "independent variable") on another variable ("called the dependent variable"). You will be given more information about the independent and dependent variables in this study at the end of today's session.

Risks or Discomforts: This is a minimal risk study. Any discomfort is expected to be temporary and not greater than you might experience in a typical day. Occasionally people may feel uncomfortable when answering questionnaires that ask about attitudes toward personal issues. While we do not anticipate that any of the questions you will be responding to are of this nature, 
if any aspect of this study makes you feel uncomfortable, you may choose not to answer certain questions, or to withdraw from the study at any time and still receive your credit.

Benefits of the Study: We anticipate that you will benefit from this study by learning more about social psychological research. When the session is over, we will describe the purpose and hypotheses of the study to you in more detail. Also, once we have completed data collection and analyses (Winter 2019) you are welcome to contact the researchers via email to view the results.

Confidentiality: Your responses in this research will be confidential and anonymous; your name will not be linked to your responses. Any materials that include your name - this consent formwill be stored separately from any other data for a minimum of 5 years. Physical materials will be stored in a locked filing cabinet in a locked room, and computer files will be stored on password-protected computers. Only the investigator and other Psychology and Law lab personnel will have access to this information. Your responses on any questionnaires will be identified only by a participant number assigned to you by the researchers. This number cannot later be used to identify you and is unrelated to your Sona ID or student number. The online questionnaire is hosted by Qualtrics, which is an American company. Consequently, Qualtrics or USA authorities may access survey data in some forms (e.g., aggregate usage information) and under strict policies. Qualtrics employs a variety of security features to make sure that the data collected are not accessible by outside bodies. More information on Qualtrics' security systems can be viewed here: https://www.qualtrics.com/security-statement/. Information regarding their privacy policy is available here: https://www.qualtrics.com/privacy-statement/ . Although Qualtrics usually stores IP address data, we have deactivated that function for this study

Incentives to Participate: You will receive 1course credit for your Introductory Psychology course. If you would prefer to walk through of the study - that is, if you would like to observe the research process but not provide any personal data - you will still be given 1 course credit. Note that while you can take part in as many psychology research studies as you wish, you cannot exceed the maximum allotted course credits, as set by your Introductory Psychology course.

Voluntary Nature of Participation: Participation in this study is voluntary. Your choice of whether or not to participate will not influence your future relations with Ryerson University. If you decide to participate, you are free to withdraw your consent and to stop your participation at any time. Should you withdraw from the study, or if you choose not to answer some questions, you will still be given your 1 course credit (provided you have not already received the maximum allotted for research participation for the term).

Dissemination of Results: Anonymized data may be provided to other researchers for the purpose of study or verification of results; any data that is shared will NOT include the names of ANY participants. It is possible that a third party (e.g., graduate students, senior undergraduate students) may have access to the data for a purpose that was not originally identified in this study. As well, results may be shared with others at scholarly meetings or as part of published papers. However, all information will be presented in aggregate form. That is, none of your individual information will be identifiable in any way. 
Questions about the Study: If you have any questions about the research now, please ask. If you have questions later about the research, you may contact.

Emma Rempel, 416, 979-5000 x 2190 erempel@psych.ryerson.ca

Dr. Tara Burke, 416-979-5000, ex. 6519, tburke@psych.ryerson.ca

If you have questions regarding your rights as a human subject and participation in this study, please contact the Ryerson University Research Ethics Board: Ryerson Ethics Board, c/o Office of the Vice President, Research and Innovation, Ryerson University 350 Victoria Street Toronto, ON M5B 2K3, 416-979-5042, rebchair@ryerson.ca

If you have questions about your participation in the Introductory Psychology Participant Pool, please contact thepool@psych.ryerson.ca

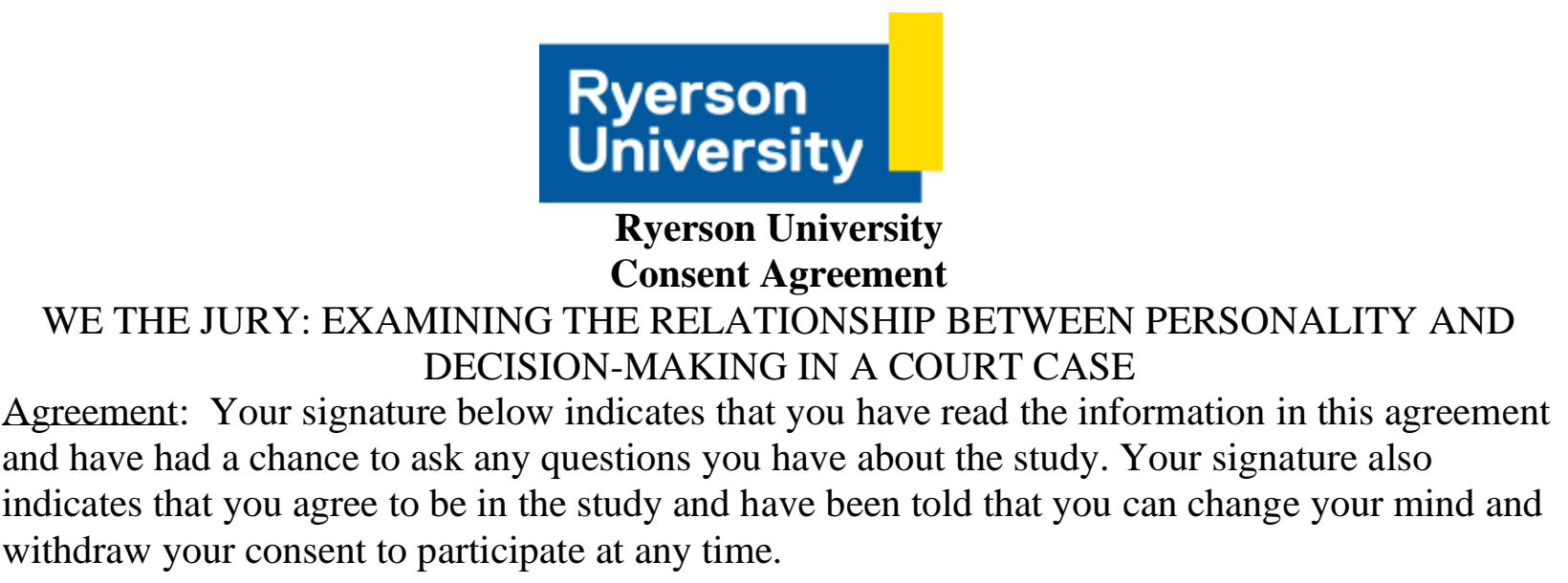

Name of Participant (please print)

Signature of Participant

Date

Signature of Investigator

Date 


\section{Appendix J}

\section{PRELIMINARY INSTRUCTION TO JURY BEFORE TRIAL}

Members of the jury, I, the Judge, am about to make some general remarks to introduce you to the trial of this case and to acquaint you with some of the general legal principles that will control your verdict decisions. These remarks are not a substitute for the more detailed instructions on the law which I will give you at the conclusion of the trial before you retire to consider your verdict.

\section{Complaint.}

This is the trial of a criminal case. The defendant, Gary Green, is charged with second-degree murder which is defined as:

1) an intentional killing that is not premeditated or planned, nor committed in a reasonable "heat of passion";

\section{OR}

2) a killing caused by dangerous conduct and the offender's obvious lack of concern for human life.

\section{Presumption of innocence and} burden of proof.

In any criminal case, the defendant is presumed to be innocent unless he or she is proven guilty beyond a reasonable doubt. The law requires the Prosecutor to prove that the defendant is guilty beyond a reasonable doubt. The law does not require the defendant to prove his (her) innocence or to produce any evidence. At the end of trial you must find the defendant not-guilty unless the Prosecutor has 
proved to you beyond a reasonable doubt that the defendant has committed the offense(s) that he (she) is charged with.

Elements of the crime.

As you have heard, the defendant is charged with the crime(s) of second-degree murder. The Prosecution must prove each of the elements which make up (that crime) (those crimes). Those elements are as follows:

- The killing was done impulsively without premeditation

- The killing resulted from an act intended to cause serious bodily harm

- The killing resulted from an act that demonstrates the perpetrators disregard or indifference to human life

\section{The trial will proceed in the following order:}

Opening statements.

Defense will have the opportunity to present opening statements. The opening statements of counsel are not evidence. We have opening statements to assist you to understand what the evidence is expected to be.

Presentation of evidence.

Next, the Prosecution will introduce evidence in support of the charge(s) in the complaint. The Defense will have the opportunity to cross-examine all of the witnesses that are testifying for the Prosecution. After that, the Defense may present evidence if they wish to, but they are not obliged to do so. Remember, the burden of proof is always on the Prosecution to prove that the defendant is guilty. The law does not require any defendant to prove his or her 
innocence or to produce any evidence at all.

Closing arguments.

After all the evidence, each side will have an opportunity to offer you arguments about what conclusions you might draw from the evidence. I again remind you that the closing arguments of the attorneys, like their opening statements, are not evidence. We have closing arguments to assist you to understand the evidence and what each party suggests that the evidence means.

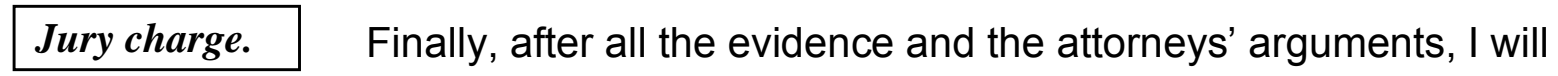
instruct you in detail on the principles of law which you are to apply to your verdict.

\section{Jury's function. Your function as the jury is to determine the facts. You} are the sole and exclusive judges of the facts. You alone determine what evidence to believe, how important any evidence is that you do believe, and what conclusions all the believable evidence leads you to. You will have to consider and weigh the testimony of all the witnesses who will appear before you, and you alone will determine whether to believe any witness and the extent to which you believe any witness. It is part of your responsibility to resolve any conflicts in testimony that may arise during the course of the trial and to determine where the truth lies. Ultimately, you must determine whether or not the Prosecution has proved the charge(s) beyond a reasonable doubt.

\section{What constitutes evidence.} You must decide this case solely on the evidence presented in the courtroom. This includes the sworn testimony of witnesses, any exhibits that I admit into evidence, any facts which I tell you have been agreed to by 
both sides, and any facts which I indicate that you may take to be a matter of common knowledge.

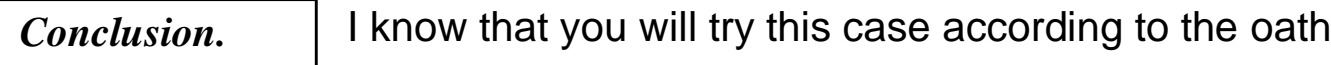
which you have taken as jurors, in which you promised that you would "well and truly try the issue between the Prosecution and the Defense according to the evidence." If you follow that oath, and try the issues without fear or prejudice or bias or sympathy, you will arrive at a true and just verdict 


\title{
Appendix K
}

\section{Verdict Instructions for Jury}

The defendant is not-guilty of second degree murder if he was justified in killing someone in self-defense. The defendant acted in lawful selfdefense if:

1. The defendant reasonably believed that he was in imminent danger of being killed or suffering great bodily injury

2. The defendant reasonably believed that the immediate use of deadly force was necessary to defend against that danger;

\begin{abstract}
AND
3. The defendant used no more force than was reasonably necessary to defend against that danger.

When deciding whether the defendant's beliefs were reasonable, consider all the circumstances as they were known to and appeared to the defendant and consider what a reasonable person in a similar situation with similar knowledge would have believed. If the defendant's beliefs were reasonable, the danger does not need to have actually existed.
\end{abstract}

As stated previously, the Prosecution has the burden of proving beyond a reasonable doubt that the killing was not justified.

If the Prosecution has not met this burden, you must find the defendant not-guilty of second-degree murder.

If the Prosecution has met this burden, you must find the defendant guilty of second-degree murder. 
Appendix L

\section{Verdict Decision}

1) What is the probability that the defendant, Gary Green, is guilty of second-degree murder? (Please report as a percentage between $0-100 \%$ )

$\%$

2) Please indicate your verdict in the case:

Guilty

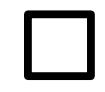

Not-guilty

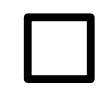

3) How confident are you in this verdict?

Please circle a value below: ( $1=$ Not at all confident, $10=$ Very confident)

$\begin{array}{llllllllll}1 & 2 & 3 & 4 & 5 & 6 & 7 & 8 & 9 & 10\end{array}$ 


\section{Appendix M}

\section{Debriefing - WE THE JURY: EXAMINING THE RELATIONSHIP BETWEEN PERSONALITY AND DECISION-MAKING IN A COURT CASE}

The recent emergence of electronic courtrooms (i.e., courtrooms that are equipped with highly advanced digital technologies) has generated novel ways for lawyers to present evidence to jurors. Computer-generated animations, which recreate or illustrate the alleged sequence of events in a crime, are increasingly being used by lawyers to present testimonial evidence to jurors. Although visual evidence has long been used in trial to illustrate the oral testimony of witnesses and experts, the potential for enhanced attention, comprehension, and persuasiveness make the use of computer-animated evidence especially appealing to many trial lawyers (Nemeth, 2011).

Although cognitive research on learning and memory indicates that animations should theoretically enhance legal judgment, jurors may use visuals in a way that biases their processing of its content (Feigenson, 2010). In fact, concerns have been raised that the vivid qualities of computer-generated displays may actually impair a juror's ability to make impartial decisions about a defendant's guilt. In the study you just participated in, we examined whether providing people with different forms of visual evidence affects how individuals process and understand the evidence, and their subsequent verdict decisions.

In the current study, all participants read a trial transcript from a police shooting case. Some participants received a transcript which had more details supporting the Defense's case, and others received a transcript that more strongly supported the Prosecution's case (an independent variable). Further, participants received Gary Green's testimony in either an oral, static visual or animated format (a second independent variable). We asked you about your comprehension of the evidence, the strength of both party's cases, and your verdict (the dependent variables).

Our first hypothesis was that when participants received testimonial evidence which was congruent with the defendant's testimony (i.e., those who received the Pro-Defense transcript) participants will render more not-guilty verdicts than those in the incongruent (i.e., ProProsecution) condition.

Our second hypothesis was that when participants received testimonial evidence in the form of a computer-generated animation, they would render a greater number of not-guilty verdicts than those in the static visual condition or oral condition, regardless of the congruence of the visual evidence with other case facts.

The information you provided during this study may allow us to help the criminal justice system develop guidelines with regards to the admissibility of computer-generated animations in court.

If you know of others who will be participating in this experiment, please refrain from discussing the study with them. We do not want our future participants to be aware of the exact procedures and expected findings. 


\section{Appendix N}

\section{SONA Ad}

The purpose of this 60 minute, 1 credit social psychological study is to examine the relationship between personality and decision-making in the context of a court case. Student's will read a transcript from a criminal case and view evidence, as well as complete questionnaires about their personalities and verdict in the case. Although the subject matter contains information about a murder, none of the material is graphic or disturbing in nature.

Overview: This study involves approximately 210 Ryerson undergraduate students currently enrolled in PSY 102/202. The study will consist of a 60-minute session on Ryerson's campus. The study may be completed in a group setting, although all activities are to be done individually. We are interested in how individuals think about the types of evidence presented in court and how they render verdicts.

Method: If you decide to participate in this research, you will be asked to read a trial transcript from a criminal case with various types of evidence. You will then receive additional evidence from an eyewitness at the crime scene. Last, you will be asked to answer some brief questionnaires assessing various aspects of your personality. You will be given 1 course credit for participating.

Risks and benefits: We do not anticipate you feeling any discomfort during the experience. Any discomfort experienced should be no more than that experienced in everyday life. You are free to withdraw from the study at any point and you may choose to not answer certain questions, and you will still receive your 1 credit for participating. While there are no direct benefits to you, you may gain a greater understanding of how social psychology research is conducted.

Location: The study will take place at the South Bond Building (105 Bond St), 2nd floor. You can take the stairs or the elevator to the second floor and have a seat in the lobby. A researcher will meet you there. If you are participating in this study on a weekend, or after 5PM, please contact us at Please call 416-979-5000 extension $x 2190$. There is a phone on the main floor lobby of the building. 


\section{References}

Allen, W. H., \& Weintraub, R. (1968). The Motion Variables in Film Presentations. Final Report.

Aronson, R. H., \& McMurtrie, J. (2007). The use and misuse of high-tech evidence by prosecutors: Ethical and evidentiary issues. Fordham Law Review, 76, 1453-1492.

Avery Cody Sr., et al. v. County of Los Angeles No. TC 023947 (L.A. Sup. Ct.)

Bala, N., \& Anand, S. (2013). Youth Criminal Justice Law. Toronto: Irwin Law

Baron, R. M., \& Kenny, D. A. (1986). The moderator-mediator variable distinction in social psychological research: Conceptual, strategic, and statistical considerations. Journal of Personality and Social Psychology, 51(6), 1173-1182.

Baumeister, R. F., Bratslavsky, E., Muraven, M., \& Tice, D. M. (1998). Ego depletion: Is the active self a limited resource?. Journal of Personality and Social Psychology, 74(5), 1262-1265.

Bell, B. E., \& Loftus, E. F. (1985). Vivid persuasion in the courtroom. Journal of Personality Assessment, 49, 659-664.

Bennett, R. B., Liebman, J. H., \& Fetter, R. E. (1999). Seeing is believing; or is it? An empirical study of computer simulations as evidence. Wake Forest Law Review, 34, 257-294.

Berry, C., \& Brosius, H. (1991). Multiple effects of visual format on TV news learning. Applied Cognitive Psychology, 5, 519-528.

Blake, T. (1977). Motion in instructional media: Some subject-display mode interactions. Perceptual and Motor Skills, 44(3), 975-985.

Campbell, K. L., Jones, L. A., \& Datny, D. B. (2013). Avatar in the courtroom: Is 3D technology ready for primetime. The Federation of Defense and Corporate Counsel, 63(4), 295-317. 
Canadian Charter of Rights and Freedoms, s 11(f), Part I of the Constitution Act, 1982, being Schedule B to the Canada Act 1982 (UK), 1982, c1.

Carson, D., \& Bull, R. (Eds.). (2003). Handbook of psychology in legal contexts. John Wiley \& Sons.

Chaiken, S. (1980). Heuristic versus systematic information processing and the use of source versus message cues in persuasion. Journal of Personality and Social Psychology, 39, 752-766.

Chaiken, S., Liberman, A., \& Eagly, A.H. (1989) Heuristic and systematic information processing within and beyond the persuasion context. In J. S. Uleman \&; J. A. Bargh (Eds.), Unintended Thought (pp. 212-252). New York: Guilford.

ChanLin, L. J. (2000). Attributes of animation for learning scientific knowledge. Journal of Instructional Psychology, 27(4), 228-228.

Chen, S., \& Chaiken, S. (1999). The heuristic-systematic model in its broader context. In S. Chaiken \& Y. Trope (Eds.), Dual-process theories in social psychology (pp. 73-96). New York: Guilford Press.

Cheng, B. K. L., \& Lo, W. H. (2012). Can news be imaginative? An experiment testing the perceived credibility of melodramatic animated news, news organizations, media use, and media dependency. Electronic News, 6, 131-150. doi: 10.1177/1931243112456531

Clark, J. M., \& Paivio, A. (1991). Dual coding theory and education. Educational Psychology, $3(3), 149-210$.

Clow, K.A. (2017). Does the 'wrongful' part of wrongful conviction make a difference in the job market? In R. Ricciardelli and A.M.F. Peters (Eds.) After Prison: Navigating Employment and Reintegration (pp. 243-257). Waterloo: Wilfrid Laurier University 
Press.

Collins, L. M., Graham, J. W., \& Flaherty, B. P. (1998). An alternative framework for defining mediation. Multivariate Behavioral Research, 33, 295-312.

Connors v. United States (1991) 112 S. Ct. 276 (5th Cir.)

Cooper, M. Q. (1998). The use of demonstrative exhibits at trial. Tulsa LJ, 34, 567-578.

Cooper, J., Bennett, E. A., \& Sukel, H. L. (1996). Complex scientific testimony: How do jurors make decisions? Law and Human Behavior, 20, 379-394.

Criminal Case Review Commission. (2015). About the criminal case review commission. Retrieved from http://www.ccrc.gov.uk/making-application/ how-it-works/

Cush, R. K., \& Delahunty, J. G. (2006). The influence of limiting instructions on processing and judgments of emotionally evocative evidence. Psychiatry, Psychology and Law, 13(1), 110-123. doi: 10.1375/pplt.13.1.110

Cutler, B. L., Dexter, H. R., \& Penrod, S. D. (1990). Nonadversarial methods for sensitizing jurors to eyewitness evidence. Journal of Applied Social Psychology, 20(14), 1197-1207.

Dahir, V.B. (2011). Digital Visual Evidence. In C. E. Henderson \& J. Epstein (Authors), The future of evidence: How science \& technology will change the practice of law (pp. 77112). Chicago, IL: American Bar Association, ABA Section of Science \& Technology Law.

Daubert v. Merrell Dow Pharmaceuticals (1993) 509 U.S. 579.

Department of Justice. (2017). Civil and criminal cases. Retrieved from Government of Canada Website http://justice.gc.ca/eng/csj-sjc/just/08.html

DeSario, N. J. (2002). Merging technology with justice: How electronic courtrooms shape evidentiary concerns. Cleveland State Law Review, 50, 57-72. 
Dixon, H. B. (2012). The evolution of a high-technology courtroom. National Center for State Courts, Future Trends in State Courts, 1(6), 28-32. Retrieved from http://ncsc.contentdm.oclc.org/cdm/ref/collection/tech/id/769

Dunn, R. (2000). Capitalizing on college students learning styles; theory, practice and research. In Dunn, R \& Griggs, R. (Eds). Practical approaches to using learning styles: in higher education (pp. 3-18). Westport, CT: Begin \& Garvey.

Dunn, M. A., Salovey, P., \& Feigenson, N. (2006). The jury persuaded (and not): Computer animation in the courtroom. Law and Policy, 28, 228-248. doi: 10.1111/j.14679930.2006.00225.x

Dunn, R. S., \& Griggs, S. A. (Eds.). (2000). Practical approaches to using learning styles in higher education. Greenwood Publishing Group.

Federal Rules of Evidence (2009). St. Paul, MN: West.

Feigenson, N. (2010). Visual evidence. Psychonomic Bulletin \& Review, 17(2), 149-154. doi: 10.1002/acp. 2900

Feigenson, N., \& Dunn, M. A. (2003). New visual technologies in court: Directions for research. Law and Human Behavior, 27(1), 109-126. doi: 10.1023/A:1021683013042

Fiedler, B. S. (2003). Are your eyes deceiving you: The evidentiary crisis regarding the admissibility of computer generated evidence. New York Law School Law Review, 48, 295-321.

Findley, K. A. (2007). Wrongful Conviction. Encyclopedia of Psychology and Law (SAGE Thousand Oaks 2007), 869-873.

Forensic Animation - 3D Vehicle Accident Recreation Services. (2018). Retrieved from https://austinvisuals.com/forensic-animation/ 
Frey, P. W., \& Adesman, P. (1976). Recall memory for visually presented chess positions. Memory \& Cognition, 4(5), 541-547.

Frye v. United States (1923) 293 F 1013 (D.C. Circ.)

Giannelli, P. C. (1993). Daubert: Interpreting the federal rules of evidence. Cardozo Law Review, 15, 1999-2026.

Gibson, S. (2006). Evolving Courtroom Technology. GPSolo Magazine, 23, 30-37. Retrieved fromhttp://www.americanbar.org/newsletter/publications/gp_solo_magazine_home/gp _so lo_magazine_index/courtroomtechnology.html

Gilovich, T., Griffin, D., \& Kahneman, D. (Eds.). (2002). Heuristics and biases: The psychology of intuitive judgment. Cambridge University Press.

Greene, E. \& Ellis, L. (2006). Decision-making in criminal justice. In D. Carson, B. Milne, F. Pakes et al. (eds.), Applying Psychology to Criminal Justice. Chichester: John Wiley \& Sons.

Hadley, M. E. M. (2009). Access to CGAs and justice: The impact of the use of computer generated animations on indigent criminal defendants' constitutional rights. Georgetown Journal of Legal Ethics, 22, 877-892.

Hafer, C. L., Reynolds, K. L., \& Obertynski, M. A. (1996). Message comprehensibility and persuasion: Effects of complex language in counterattitudinal appeals to laypeople. Social Cognition, 14, 317-337. doi:10.1521/soco.1996.14.4.317

Hans, V. P., Kaye, D. H., Dann, B. M., Farley, E. J., \& Albertson, S. (2011). Science in the jury box: Jurors' comprehension of mitochondrial DNA evidence. Law and Human Behavior, 35(1), 60-71. doi: 10.1007/s10979-010-9222-8 
Hayes, A. F. (2017). Introduction to mediation, moderation, and conditional process analysis: A regression-based approach. Guilford Publications.

Höffler, T. N., \& Leutner, D. (2007). Instructional animation versus static pictures: A metaanalysis. Learning and instruction, 17(6), 722-738. doi:

10.1016/j.learninstruc.2007.09.013

Huff, C. R. (2002). Wrongful conviction and public policy: The American Society of Criminology 2001 presidential address. Criminology, 40(1), 1-18.

Huff, C. (2004). Wrongful convictions: The American experience. Canadian Journal of Criminology and Criminal Justice, 46(2), 107-120.

Innocent Canada. (2018). About Us. Retrieved from http://www.innocencecanada.com/about-us/

Innocence Network. (2019). About the Innocence Network. Retrieved from https://www.innocencenetwork.org/about

Innocence Project. (2017). Exonerate the Innocent. Retrieved from https://www.innocenceproject.org/exonerate/

Kahneman, Daniel. (2011) Thinking, fast and slow. New York: Farrar, Straus and Giroux.

Kassin, S. M., \& Dunn, M. A. (1997). Computer-animated displays and the jury: Facilitative and prejudicial effects. Law \& Human Behavior, 21, 269-281.

Kassin, S.M., \& Wrightsman, L.S., (1983). The construction and validation of a Juror Bias Scale. Journal of Research in Personality, 17, 423-442.

Kenny, D. A., Kashy, D. A., \& Bolger, N. (1998). Data analysis in social psychology. In D. Gilbert, S. T. Fiske, \& G. Lindzey (Eds.), Handbook of Social Psychology (4th ed., Vol. 1, pp. 233-265). New York: McGraw-Hill.

Koehler, J. (2006). Train our Jurors. Heuristics and the Law. Gerd Gigerenzer und Christoph 
Engel. Cambridge, MIT Press: 303-326.

Koehler, J. J., Schweitzer, N. J., Saks, M. J., \& McQuiston, D. E. (2016). Science, technology, or the expert witness: What influences jurors' judgments about forensic science testimony?. Psychology, Public Policy, and Law, 22(4), 401-413. doi:

10.1037/law0000103

Konoske, P. J., \& Ellis, J. A. (1986). Cognitive factors in learning and retention of procedural tasks (No. NPRDC-TR-87-14). Navy Personnel Research and Development Center San Diego, CA.

Krieger, S. A. (2011). Why our justice system convicts innocent people, and the challenges faced by innocence projects trying to exonerate them. New Criminal Law Review, 14(3), 333402. doi: $10.1525 /$ nclr.2011.14.3.333

Lawless, J. (2016). Prosecutorial Misconduct (4th ed.). LexisNexis.

Legate, B. L. (2006). The Admissibility of Demonstrative Evidence in Jury Trials: Applying the Principled Approach to the Law of Evidence. Advocates'Quarterly., 31, 316-346.

Louie, D. M., Rincon, C., Anderson, V. R., \& Kayfetz, P. (2007). Use and admissibility of high definition video visibility Studies, computer animations and computer simulations. Quarterly-Federation of Defense and Corporate Counsel. 58(1), 87-107.

Maxwell, A. (2017). Adult criminal court statistics in Canada, 2014/2015. Juristat: Canadian Centre for Justice Statistics, 2, 85-002.

Mayer, R. E. (2001). Multimedia learning. Cambridge: Cambridge University Press.

Mayer, R. E., \& Moreno, R. (2002). Animation as an aid to multimedia learning. Educational Psychology Review, 14(1), 87-99. doi: 1040-726X/02/0300-0087/0

Mayer, R. E., \& Sims, V. K. (1994). For whom is a picture worth a thousand words? Extensions 
of a dual-coding theory of multimedia learning. Journal of Educational Psychology, 86, $389-401$.

Moreno, R., \& Mayer, R. E. (1999). Cognitive principles of multimedia learning: The role of modality and contiguity. Journal of Educational Psychology, 91(2), 358-368.

Muraven, M., \& Baumeister, R. F. (2000). Self-regulation and depletion of limited resources: Does self-control resemble a muscle?. Psychological bulletin, 126(2), 247.

Nadal, K. L., \& Davidoff, K. C. (2015). Perceptions of police scale (POPS): Measuring attitudes towards law enforcement and beliefs about police bias. Journal of Psychology and Behavioral Science, 3, 1-9. doi: 10.15640/jpbs.v3n2a1

National Registry of Exonerations. (2019). Exonerations by year and type of crime. Retrieved from https://www.law.umich.edu/special/exoneration/Pages/Exoneration-by-YearCrime-Type.aspx

Nemeth, R. J. (2011). Enhanced persuasion in the courtroom: Visually dynamic demonstrative evidence and juror decision making. In Handbook of trial consulting (pp. 203-214). Springer, Boston, MA.

Norris, G. (2015). Judgement heuristics and bias in evidence interpretation: The effects of computer generated exhibits. International Journal of Law and Psychiatry, 42, 121127. doi: 10.1016/j.ijlp.2015.08.016

Ogloff, J. R. P., \& Rose, V. G. (2005). The Comprehension of Judicial Instructions. In N. Brewer \& K. D. Williams (Eds.), Psychology and law: An empirical perspective (pp. 407-444). New York, NY, US: The Guilford Press.

Ontario Ministry of the Attorney General. (2015). Technology in the Civil Justice System. 
Retrieved from https://www.attorneygeneral.jus.gov.on.ca/english/about/pubs/cjrp/180_ technology.php

Paciocco, D. M., \& Stuesser, L. (2015). The law of evidence. Toronto, ON: Irwin Law.

Paivio, A. (1969). Mental imagery in associative learning and memory. Psychological Review, $61,179-211$.

Paivio, A. (1971). Imagery and verbal processes. New York: Holt.

Paivio, A. (1986). Mental representations: A dual coding approach. New York: Oxford University Press.

Parisi, F. (2002). Rent-seeking through litigation: adversarial and inquisitorial systems compared. International Review of Law and Economics, 22(2), 193-216.

Park, J., \& Feigenson, N. (2013). Effects of a visual technology on mock juror decision making. Applied Cognitive Psychology, 27(2), 235-246. doi: 10.1002/acp.2900

Pennington, N., \& Hastie, R. (1992). Explaining the evidence: Tests of the Story Model for juror decision making. Journal of Personality and Social Psychology, 62(2), 189-206.

People v. Mitchell (1992) No. 12462 (Cal. Super. Ct.)

Petty, R. E. \& Cacioppo, J. T. (1986). Communication and persuasion: Central and peripheral routes to attitude change. New York, NY: Springer-Verlag.

Ramsey, R. J., \& Frank, J. (2007). Wrongful conviction: Perceptions of criminal justice professionals regarding the frequency of wrongful conviction and the extent of system errors. Crime \& Delinquency, 53(3), 436-470. doi: 10.1177/0011128706286554

Rempel, E., Hamovitch, L., Zannella, L., Burke, T.M. (in press) The power of technology: Examining the effects of digital visual evidence on jurors' processing of trial information. Applied Cognitive Psychology, doi: 10.1002/acp.3598 
Rieber, L. P. (1991). Animation, incidental learning, and continuing motivation. Journal of Educational Psychology, 83(3), 318-328. doi: 10.1037/0022-0663.83.3.318

Roach, K. (2012). Wrongful convictions in Canada. University of Cincinnati Law Review, 80(4), $1465-1526$.

Rosen, P. (1992). Wrongful convictions in the criminal justice system. Library of Parliament, Research Branch.

R vs. Mohan (1994) 2 SCR 9 (S.C.C.)

Schofield, D. (2011). Playing with evidence: Using video games in the courtroom. Entertainment Computing, 2(1), 47-58. doi: 10.1016/j.entcom.2011.03.010

Schofield, D., \& Mason, S. (2007). Using graphical technology to present evidence. Electronic Evidence: Disclosure, Discovery and Admissibility (pp. 217-253). London: Lexis-Nexis.

Selbak, J. (1994). Digital litigation: The prejudicial effects of computer-generated animation in the courtroom. High Technology Law Journal, 9(2), 337-367.

Shrout, P. E., \& Bolger, N. (2002). Mediation in experimental and nonexperimental studies: new procedures and recommendations. Psychological Methods, 7(4), 422-445. doi: 10.1037//1082-989X.7.4.422

Stanovich, K. E., \& West, R. F. (2000). Individual differences in reasoning: Implications for the rationality debate?. Behavioral and brain sciences, 23(5), 645-665. doi: 0140$525 \mathrm{X} / 00$

State v. Mulligan (1997) 97 Wn. App. 261 (Wash. Ct. App.)

State v. Phillips (2004) 123 Wn. App. 761 (Wash. Ct. App.)

Stiff, J. B. (1986). Cognitive processing of persuasive message cues: A meta-analytic review of the effects of supporting information on attitudes. Communications Monographs, 53(1), 
75-89.

Tay, S. W., Ryan, P., \& Ryan, C. A. (2016). Systems 1 and 2 thinking processes and cognitive reflection testing in medical students. Canadian medical education journal, 7(2), 97103.

Tversky, A., \& Kahneman, D. (1973). Availability: A heuristic for judging frequency and probability. Cognitive psychology, 5(2), 207-232.

U.S. Constitution, Amendment 6

van Caenegem, W. (1999). Advantages and disadvantages of the adversarial system in criminal proceedings. Law Review Commission of Western Australia, 1, 69-102.

Vinson, D. E., \& Davis, D. S. (1993). Jury persuasion: Psychological strategies \& trial techniques. Prentice Hall Law \& Business.

Waters, N., Gallegos, A., Green, J., \& Rozsi, M. (2015, September). Criminal Appeals in State Courts (United States, U.S. Department of Justice, Office of Justice Programs). Retrieved February 18, 2018, from https://www.bjs.gov/index.cfm?ty=pbdetail\&iid=5368

Weiss, H., \& McGrath, J.B. (1963). Technically speaking: oral communication for engineers, scientists and technical personnel. New York: McGraw-Hill.

Wetzel, C. D., Radtke, P. H., \& Stern, H. W. (1994). Instructional effectiveness of video media. Lawrence Erlbaum Associates, Inc.

Wiggins, E. C. (2004). What we know and what we need to know about the effects of courtroom technology. William and Mary Bill of Rights Journal, 12(3), 731-743.

Wolfe, J. M., \& Horowitz, T. S. (2004). What attributes guide the deployment of visual attention and how do they do it?. Nature Reviews Neuroscience, 5(6), 495-502. 
Zalman, M., Smith, B., \& Kiger, A. (2008). Officials' estimates of the incidence of "actual innocence" convictions. Justice Quarterly, 25(1), 72-100. doi:

$10.1080 / 07418820801954563$ 